\title{
The Role of the Food Matrix and Gastrointestinal Tract in the assessment of biological properties of ingested engineered nanomaterials (iENMs): State of the science and knowledge gaps
}
David Julian McClements ${ }^{\mathrm{a} *}$, Glen DeLoid ${ }^{\mathrm{b}}$, Georgios Pyrgiotakis ${ }^{\mathrm{b}}$, Jo Anne Shatkin ${ }^{\mathrm{c}}$, Hang $\mathrm{Xiao}^{\mathrm{a}}$ and Philip Demokritou ${ }^{\mathrm{b} *}$

${ }^{a}$ Department of Food Science, University of Massachusetts Amherst, Amherst, MA 01003, USA

${ }^{\mathbf{b}}$ Laboratory for Environmental Health NanoScience (LEHNS)

Center for Nanotechnology and Nanotoxicology, T. H. Chan School of Public Health, Harvard University, 665 Huntington Avenue, Boston, MA 02115, USA

${ }^{\mathbf{c}}$ Vireo Advisors, LLC. PO Box 51368, Boston, MA 02205, USA

\section{"corresponding authors:}

David Julian McClements, Department of Food Science, University of Massachusetts Amherst,Amherst, MA 01003,USA.mcclements@foodsci.umass.edu; Tel: 4135451019.

Philip Demokritou, Center for Nanotechnology an nanotoxicology, T.H. Chan School of Public Health, Harvard University, Boston MA 02115, email: pdemokri@hsph.harvard.edu, Tel 617 432-3481, Web: www.hsph.harvard.edu/nano 
Key Words: engineered nanomaterials; nanotoxicology; gastrointestinal tract; food matrix effects; food nanotechnology; in vitro models

\footnotetext{
ABSTRACT

Many foods contain appreciable levels of engineered nanomaterials (ENMs) (diameter $<$ $100 \mathrm{~nm}$ ) that may be either intentionally or unintentionally added. These ENMs vary considerably in their compositions, dimensions, morphologies, physicochemical properties, and biological responses. From a toxicological point of view, it is often convenient to classify ingested ENMs (iENMs) as being either inorganic (such as $\mathrm{TiO}_{2}, \mathrm{SiO}_{2}, \mathrm{Fe}_{2} \mathrm{O}_{3}$, or $\mathrm{Ag}$ ) or organic (such as lipid, protein, or carbohydrate), since the former tend to be indigestible and the latter are generally digestible. At present there is a relatively poor understanding of how different types of iENMs behave within the human gastrointestinal tract (GIT), and how the food matrix and biopolymers transform their physico-chemical properties and influence their gastrointestinal fate. This lack of knowledge confounds an understanding of their potential harmful effects on human health. The purpose of this article is to review our current understanding of the GIT fate of iENMs, and to highlight gaps where further research is urgently needed in assessing potential risks and toxicological implications of iENMs. In particular, a strong emphasis is given to the development of standardized screening methods that can be used to rapidly and accurately
} 
assess the toxicological properties of iENMs.

Abbreviations: ENM: engineered nanomaterial; iENM: ingested engineered nanomaterial; GI: gastrointestinal; GIT: gastrointestinal tract; GRAS: generally regarded as safe; $\mathrm{TiO}_{2}$ : titanium dioxide, $\mathrm{SiO}_{2}$ : silicon dioxide; $\mathrm{Fe}_{2} \mathrm{O}_{3}$ : iron (III) oxide; $\mathrm{Fe}_{3} \mathrm{O}_{4}$ : iron (II, III) oxide; Ag: silver; SAR: Structure-activity relationship; SERS: Surface-enhanced Raman spectroscopy; sp-ICP-MS: single particle inductively coupled plasma mass spectrometry; FFF: field flow fractionation; XANES: X-ray absorption near edge structure; SEM: scanning electron microscopy; TEM: transmission electron microscopy. 


\section{Introduction}

Many foods contain organic or inorganic particles that have dimensions in the nanoscale range, generally defined as having at least one dimension less than $100 \mathrm{~nm}$ (Figure 1). It is worth pointing out that the $100 \mathrm{~nm}$ size cut off is arbitrarily selected and that other properties in addition to size may contribute to the unique properties of such materials. These nanoparticles may be naturally present in foods, intentionally added to achieve a particular functional attribute, or unintentionally introduced through the environment, ingredients, packaging or processing operations (Bellmann et al., 2015; Szakal et al., 2014a; Yada et al., 2014b). Naturally occurring nanoparticles in food include the casein micelles found in milk, which typically have dimensions in the range from a few tens of nanometers to a few hundred nanometers (Holt et al., 2003; Livney, 2010). Organic engineered nanomaterials (ENMs) are often intentionally added to foods or beverages to encapsulate vitamins, nutraceuticals, flavors, colors, or antimicrobials (Livney, 2015; McClements et al., 2015; Shin et al., 2015; Yao et al., 2015b). Inorganic ENMs are intentionally added to foods for numerous reasons: $\mathrm{TiO}_{2}$ is added to provide opacity and brightness (Weir et al., 2012); $\mathrm{SiO}_{2}$ nanoparticles are added to modify food texture and powder flow characteristics (Dekkers et al., 2011; Peters et al., 2012); iron oxides $\left(\mathrm{Fe}_{2} \mathrm{O}_{3}\right.$ or $\left.\mathrm{Fe}_{3} \mathrm{O}_{4}\right)$ are added to provide bioavailable iron for nutritional purposes (Raspopov et al., 2011; Zimmermann and Hilty, 2011) or as colorants; and, Ag nanoparticles are added as antimicrobial agents (Hajipour et al., 2012).

ENMs may also be introduced into food products unintentionally during the food manufacturing process. There may be nanoparticles present in the air or the water used within a food processing facility that find their way into the final product. Certain food ingredients containing micron-sized particles have been approved for use in food by regulatory authorities, 
and are generally regarded as safe (GRAS), without the need of characterization or definition of particle size. However, these ingredients may also contain ENMs that the food manufacturer is unaware of. For example, food grade $\mathrm{TiO}_{2}$ particles are used as lightening agents to increase the whiteness of foods, and so they are usually designed to have dimensions similar to the wavelength of light (a few hundred nanometers) so as to maximize their light scattering efficiency. However, there may be a population of nano-scale particles present within commercial ingredients (Warheit et al., 2015). For example, food grade $\mathrm{TiO}_{2}(\mathrm{E} 171$ - European designation) contains nano-scale particles (Athinarayanan et al., 2015), and the presence of nano-sized $\mathrm{TiO}_{2}$ has been reported in dietary supplements (Lim et al., 2015) and certain food products (Peters et al., 2014). Likewise, nanoscale $\mathrm{SiO}_{2}$ particles have been reported in food grade $\mathrm{SiO}_{2}$ ingredients (E551) and at levels of up to $14.4 \mu \mathrm{g} / \mathrm{g}$ in commercial foods and dietary supplements (Athinarayanan et al., 2015; Athinarayanan et al., 2014; Dekkers et al., 2011; Lim et al., 2015). Furthermore, mechanical size reduction operations commonly used in the food industry, such as grinding, homogenization, or spray drying, typically produce a distribution of particle sizes, and some of these particles may also fall in the nanoscale range (McClements, 2011). In addition, packaging materials may contain functional ENMs that migrate into a food or beverage product during storage (Abdul Khalil et al., 2016; Aulin et al., 2012; Costa et al., 2014; Dehnad et al., 2014; El-Wakil et al., 2015; Pezzuto et al., 2015). It is also possible that solutes could migrate into a food and precipitate due to the change in their thermodynamic environment, thereby leading to the formation of nanoparticles in a food.

The physicochemical and physiological properties of particles may change considerably when their dimensions fall within the nanoscale range, e.g., chemical reactivity, mechanical strength, digestibility, transport properties, and cellular uptake, accumulation, and distribution 
(Acosta, 2009; Buzea et al., 2007; Cohen et al., 2014a; Davidson et al., 2016; Konduru et al., 2015; Konduru et al., 2014; Konduru et al., 2016; Lu et al., 2016a; Lu et al., 2016b; Ma et al., 2015; Pirela et al., 2016a; Pirela et al., 2016b; Sisler et al., 2015; Sotiriou et al., 2014; Watson et al., 2014; Yokel et al., 2014; Zhou et al., 2014). These changes are associated with the smaller particle dimensions and higher surface areas of nanoparticles compared to larger particles, as well as to quantum effects taking place in the nanoscale (Pyrgiotakis et al., 2014; Pyrgiotakis et al., 2013).

Consequently, food consumers, manufacturers, and regulators are concerned about the potential health risks associated with ENMs in foods (Bouwmeester et al., 2009; Bugusu et al., 2009; Yada et al., 2014b). Knowledge of the impact of ingested ENM characteristics on their GI fate is currently rather limited. In addition, there is a lack of standardized protocols and methodologies to assess the GI fate of ingested engineered nanomaterials (iENMs), and their potential toxicity (Contado, 2015; Szakal et al., 2014a; Szakal et al., 2014c).

The purpose of this article is to provide a brief overview of the current understanding of the GI fate of iENMs, to outline major knowledge gaps and challenges in assessing their potential toxicological effects, to highlight areas where there is a lack of knowledge, and to indicate where further research is needed.

\section{Intrinsic properties of iENMs}

iENMs may vary considerably in their properties (Figure 2), which will alter their GIT fate and potential toxicity. Some of the most important ways that the properties of food-grade ENMs may vary are highlighted below: 
- Composition: ENMs may be formed from organic substances (such as lipids, proteins, and carbohydrates) or inorganic substances (such as $\mathrm{Ag}, \mathrm{SiO}_{2}, \mathrm{TiO}_{2}$, and $\mathrm{Fe}_{2} \mathrm{O}_{3}$ ). The composition of an ENM has a major impact on its fate within the GIT. Many organic substances are digested by enzymes within the GIT, whereas many inorganic substances may not be digested, but may be dissolved in certain regions of the GIT due to changes in $\mathrm{pH}$ or dilution (Dekkers et al., 2011). Nanoparticles may also impact the intestinal microbiome. For example Williams et al. reported size- and dose-dependent changes in ileal-mucosal bacterial populations, including a shift toward gram negative organisms, in rats gavaged with silver nanoparticles (Williams et al., 2015). The chemical reactivity and toxicity of inorganic ENMs is also closely related to their composition, e.g., gold nanoparticles tend to have a relatively low chemical reactivity and toxicity (Khalili Fard et al., 2015; Pradeep and Anshup, 2009), whereas silver nanoparticles tend to be relatively highly reactive and toxic due to the release of ions (Brasiliense et al., 2016; Khalili Fard et al., 2015).

- Structure: Pristine ENMs vary greatly in their initial size, morphology, crystallinity, porosity, and aggregation state, depending on the materials and processing operations used to fabricate them (Yada et al., 2014b). Nanoparticle structure is likely to have a major impact on their fate within the GIT, e.g., their ability to pass through biological barriers such as the mucus layer or epithelium cells, or to interact with other substances within the GIT (Bellmann et al., 2015). In particular, the association (aggregation or agglomeration) of primary ENMs with each other is likely to be particularly important. It should be noted that the closely related terms aggregation and agglomeration have different meanings here, particularly in the context of inorganic ENMs. Herein we will use aggregation to indicate the fusing of primary ENM particles that occurs during their synthesis, and agglomeration to 
refer to the looser associations, generally governed by Van der Waals, electrostatic, and hydrophobic forces, between ENMs that are dispersed in liquids. Whereas aggregation state is generally stable after synthesis (in the absence of dissolution or the application of extreme forces or conditions) agglomeration state is often dynamically changing, and easily altered by changes in the extrinsic properties of the suspending media (i.e., $\mathrm{pH}$, ionic strength, protein content)(Cohen et al., 2013). A further distinction is that aggregates are composed of the ENM material only, whereas agglomerates include media and media components trapped between or adsorbed onto the primary ENM particles (e.g. the protein corona)(DeLoid et al., 2014). The effect of the protein coronoa on nano-bio interactions is well understood and noted in the nanotoxicology research(Kelly et al., 2015; Monopoli et al., 2011a; Pyrgiotakis et al., 2014; Pyrgiotakis et al., 2013).

- Interfacial Properties: The nature of the substances located at the surfaces of ENMs influence their interfacial properties, such as chemical reactivity, thickness, rheology, charge, polarity, and protein corona. These interfacial characteristics may also influence the GIT fate of nanoparticles, such as their penetration through biological barriers, interactions with other substances, and agglomeration state and stability.

The intrinsic properties of iENMs would be expected to play a major role in determining their biological fate and potential toxicity. However, there is currently a relatively poor understanding of how the initial composition, structure, and interfacial properties of food-grade nanoparticles influence their behavior within the complex environment of the human GIT (Magnuson et al., 2011; Powell et al., 2010; Weir et al., 2012) and impact their biokinetics and toxicity. Several studies have attempted to correlate various metal oxide ENM physiochemical descriptors with measurements of in vitro toxicity in order to develop structure-activity 
relationships (SARs). (Liu et al., 2014; Liu et al., 2013). Molecular SARs have been extensively and successfully used in the field of drug discovery and development (Akhtar et al., 2016; Cordomi et al., 2016; Monteiro et al., 2016; Putz et al., 2016; Sharma et al., 2016). Likewise the ultimate goal of developing nano-SARs is to enable prediction of toxicity based on ENM intrinsic physicochemical properties and thus enable safer by design development of commercial ENMs. Clearly there is a need to develop SARs specifically for iENMs to understand their potential toxicological implications, and this will be an important area for systematic study in the future.

\section{3. iENM property transformations: Impact of GIT Conditions}

The initial physicochemical properties and structural characteristics of ingested engineered nanoparticles will impact their GI fate in a number of ways: (i) they may influence their interactions with other components in the GI fluids (such as enzymes, bile salts, phospholipids, and biopolymers); (ii) they may influence their agglomeration state and stability within different GIT regions; (iii) they may impact their passage through the mucus layer that coats the intestinal lining; (iv) they may influence their transport into and across the epithelium cells, e.g., enterocytes and M-cells; (v) they may impact their interaction with colonic bacteria in the large intestine (Bellmann et al., 2015; Bouwmeester et al., 2009; Ensign et al., 2012; Frohlich and Roblegg, 2012; Magnuson et al., 2011; Powell et al., 2010). One of the major limitations of many previous studies of the potential GIT fate of iENMs has been the use of over-simplistic cellular model systems that ignore the potential influence of GIT conditions on nanoparticle characteristics (Szakal et al., 2014a). For example, the absorption of iENMs is often measured by directly incubating "pristine" nanoparticle suspensions with model intestinal cells rather than 
passing them through a GIT model first. Furthermore, these pristine ENMs are usually incubated a culture medium that contains serum proteins, which results in protein corona formation and agglomeration that will affect the bioactivity and biological properties of the nanoparticles (Cohen et al., 2013; Lundqvist et al., 2011; Monopoli et al., 2011b; Tenzer et al., 2013; Walkey and Chan, 2012). In addition, these simple cellular models ignore the effects of agglomeration on the mass transport and dosimetry of the iENMs, thereby resulting in erroneous and difficult to interpret dose-response data (Cohen et al., 2015; Cohen et al., 2014b; DeLoid et al., 2014; DeLoid et al., 2015). Consequently, the interfacial properties and agglomeration state of the iENMs are not physiologically relevant and may be very different from what the intestinal cells would encounter in real life. Commonly used in vitro cellular approaches have significant deficiencies and may lead to misleading or erroneous conclusions being made about the impact of specific iENM characteristics on their GI fate and biological properties.

An improved understanding of the fate of iENMs should therefore take into consideration the complex physicochemical and physiological processes that occur as they pass through the human GIT (Yada et al., 2014b) and their transformations. After ingestion ENMs may move through the mouth, stomach, small intestine, and large intestine. A summary of the different environments that iENMs experience within these different regions of the GIT is given in Figure 3. During this journey the iENMs are exposed to: (i) changes in $\mathrm{pH}$ and ionic composition; (ii) surface active components (e.g., bile salts, phospholipids, fatty acids, proteins); (iii) digestive enzymes (e.g., amylases, proteases, lipases); (iv) biopolymers (e.g., proteins, mucins); (v) biological surfaces (e.g., tongue, esophagus, stomach, intestine); (vi) intestinal microbes (e.g., colonic bacteria); and, (vii) complex flow/force profiles (Blijdenstein et al., 2004; de Hoog et al., 2006; Gwartney et al., 2004; Malone et al., 2003a; Malone et al., 2003b; Silletti et al., 
2007; Vingerhoeds et al., 2005). As a result, the composition, size, shape, charge, dissolution, and agglomeration state of iENMs may change considerably as they travel through the GIT (Figure 4). This has important consequences for determining their overall GI fate, e.g., whether they are digested, dissolved, absorbed by intestinal cells, or reach the colon. Inorganic iENMs may also be distributed throughout the body after absorption and may accumulate in specific organs, which may impact their toxicity (Cha et al., 2008; Kim et al., 2010; Konduru et al., 2015; Konduru et al., 2016; Kulthong et al., 2012; Park et al., 2010; Zhang et al., 2013). It is often possible to carry out a comprehensive analysis of the intrinsic properties of pristine ENMs before they are intentionally added to foods because they are isolated in a simple liquid or powder form. Thus, it is possible to measure their initial particle size distribution, shape, composition, surface chemistry, and surface charge using conventional methods (Singh et al., 2014; Szakal et al., 2014a; Szakal et al., 2014c). However, these intrinsic ENM properties may change considerably when the nanoparticles encounter the complex environment of the human GIT. Some of the potential changes of nanoparticles that may occur are highlighted in Figure 4, and briefly discussed below:

- Interfacial composition and properties: The nature of the molecular species at the surface of iENMs may change for a number of reasons. The GIT contains numerous types of surfaceactive molecules that may come from the ingested food (such as surfactants, free fatty acids, monoacylglycerols, proteins, peptides, and phospholipids) or be secreted by the human body (such as mucin, proteins, phospholipids, and bile salts). These surface-active molecules may adsorb to the nanoparticle surfaces and alter interfacial composition. Depending on the system, they may also adsorb to bare nanoparticle surfaces (adsorption), they may displace existing surface-active molecules from nanoparticle surfaces (competitive adsorption), or 
they may adsorb between or on top of existing surface-active molecules (co-adsorption). The resulting changes in interfacial composition, structure, properties, and charge will alter the subsequent fate of the iENMs.

- Core composition and properties: The internal composition of iENMs may also change appreciably as they pass through the different regions of the GIT. The composition of digestible ENMs may be altered due to their hydrolysis by digestive enzymes in the GIT fluids. Water, salts, and other components may diffuse in or out of a nanoparticle and cause it to swell or shrink, thereby altering its composition. Nanoparticles may chemically react with other components in the GIT fluids thereby altering their composition, e.g., due to oxidation reactions.

- Dimensions and agglomeration state: The size of the individual ENMs present within a food may either increase or decrease as they pass through the GIT. Particles that are susceptible to dissolution or degradation in GIT fluids may decrease in dimensions within the GIT. For example, lipid or protein nanoparticles are digested by lipases and proteases, whereas some organic nanoparticles dissolve or dissociate under the highly acidic conditions of the stomach (Axson et al., 2015; Salvia-Trujillo et al., 2015; Zou et al., 2016). On the other hand, initially small particles may increase in dimensions as they pass through the GIT due to agglomeration, coalescence, and flocculation. Certain types of lipid nanoparticles coalesce in the GIT and form larger particles that can no longer be considered to be in the nanoscale range (Salvia-Trujillo et al., 2013). Inorganic ENMs often form agglomerates in liquid suspension, typically consisting of multiple protein-coated primary particles interspersed with suspending liquid. While the surfaces of such agglomerates contain nano-scale features, the agglomerates themselves, like coalesced organic particles, are often not strictly in the 
nanoscale range. In some cases, very large numbers of agglomerates can also flocculate to form macroscopic structures. Obviously, these changes in particle dimensions will impact the subsequent GI fate of the nanoparticles and should be taken into account. The dimensions of iENMs that are comprised of substances that have an appreciable solubility in water may also undergo changes in their dimensions due to Ostwald ripening processes, i.e., the diffusion of molecules from small to large particles through the intervening medium (Li et al., 2009; Wooster et al., 2008).

- Physical state: iENMs may be fabricated from materials that are liquid or solid (amorphous or crystalline). The physical state of nanoparticles may change as they pass through the GIT due to alterations in temperature or solution conditions, which will impact their GI fate. A solid-liquid phase transition may occur at a temperature around the melting point of nanoparticles or at a concentration around their solubility limit. The physical state of lipid nanoparticles has been shown to impact their digestibility by lipase (Bonnaire et al., 2008), as well as their stability to partial coalescence (Golding et al., 2011), which altered their GIT fate. Knowledge of the physical state of nanoparticles in different regions of the GIT may therefore be important for understanding and controlling their behavior.

In vitro cellular tests developed to understand and predict the biological behavior of iENMs should therefore take these complex events into account; otherwise they will give unrepresentative results. As mentioned earlier, transformations in the properties of iENMs as they travel through the GIT are rarely considered in in vitro studies, preventing risk assessors from accurately assessing or quantifying potential impacts. 


\section{4. iENM property transformations: Impact of Food Matrix Effects}

Foods and beverages are highly complex materials that vary considerably in their compositions, structures, and properties. They may have different $\mathrm{pH}$ values, ionic strengths, and ingredient types. They may be liquid, semi-solid, or solid. They may be homogeneous or heterogeneous at different length scales. They may be clear, turbid, or opaque. During processing and preparation, foods may be exposed to different mechanical forces and temperature profiles. The introduction of nanoparticles into these complex materials may alter the properties of both the nanoparticles and the foods. It is often difficult using existing techniques to characterize the properties of ENMs within foods because food matrices have such complex compositions and structures, and complete characterization of ENMs in food matrices may require development of new methods (Bellmann et al., 2015; Szakal et al., 2014a). Other analytical tools that might be used to provide valuable information about nanoparticle characteristics in the complex milieu of the GIT include Surface-enhanced Raman spectroscopy (SERS) (Taylor et al., 2016), single particle inductively coupled plasma mass spectrometry (spICP-MS) (Ma et al., 2016; Montano et al., 2016), Field flow fractionation (FFF) (Laborda et al., 2016; Zattoni et al., 2014), X-ray absorption near edge structure (XANES) (Grafe et al., 2014; Kuzmin and Chaboy, 2014) and scanning and transmission electron microscopy (SEM and TEM).

In this section, we highlight some of the ways in which the food matrix may impact the properties of iENMs.

\subsection{Within the food product}

When pristine ENMs are mixed with a complex food matrix there may be appreciable 
alterations in a number of their properties: interfacial composition and properties; core composition and properties; dimensions and agglomeration state; physical state. These factors are similar to those discussed in the previous section on the impact of GIT conditions on ENM properties, and therefore will not be considered in detail here. Another important consideration is the physical location of the iENMs within the food matrix. For example, in heterogeneous foods that contain lipid, water, and biopolymer components, the nanoparticles may be dispersed in the water phase, in the oil phase, at the oil-water interface, or they may be associated with biopolymers (Yada et al., 2014a). It should be noted that many foods already contain other particles with dimensions in the nano-scale or micro-scale levels, and the presence of these particles may interfere with the isolation and characterization of the iENMs of interest.

\subsection{Within the GIT}

The nature of the food that is co-ingested with iENMs may also have a major impact on their GIT fate (Bellmann et al., 2015). Consequently, the biological effects of a particular type of nanoparticle may change appreciably depending on the type and amount of food or beverage that it is consumed with. The interactions of iENMs with food matrices and potential effects on their physico-chemical properties is often ignored when considering their potential toxicity and should be taken into account (Cohen et al., 2013; Gerloff et al., 2013; Zeeb et al., 2015). In this section, some of the ways that the food matrix may influence the potential GIT fate of ingested nanoparticles are discussed.

The environment of the iENMs in a food will be changed appreciably when the food matrix passes through the GIT for a number of reasons (Norton et al., 2015). First, the food is diluted with GI fluids secreted from the mouth, stomach, and small intestine, which will alter the $\mathrm{pH}$ and ionic strength of the surrounding fluid by an amount that depends on the type and level of food 
ingested. Second, macronutrients are hydrolyzed by digestive enzymes in the GIT, thereby breaking down structures present in the original food and altering the chemical composition of the GIT fluids. Third, the GI fluids contain surface-active substances arising from the food and GIT secretions, such as fatty acids, monoacylglycerols, proteins, bile salts, phospholipids, and mucin, which may adsorb to the surfaces of the iENMs. Fourth, the iENM-food matrix mixture will be exposed to complex shear flows/forces within the GIT that may alter the agglomeration state of the iENMs . Thus, the type, amount, and interactions of the ingredients present within the original food will alter the GIT environment that the iENMs are exposed to during their passage through the mouth, stomach, small intestine, and colon. Therefore, the interactions between food and GIT components and the intrinsic properties of pristine iENMs will define their fate and biological properties, and such complex transformations need to be included in cellular studies

\section{Assessing the GIT Fate and Toxicity of iENMs: Challenges and knowledge gaps}

Data on GIT fate and toxicity of iENMs continue to grow. However major knowledge gaps still remain prohibiting risk assessors to understand potential implications from families of iENMs. In more detail:

\subsection{GIT Fate}

The properties of pristine nanoparticles in a simple powder or liquid can usually be characterized using existing methodologies: light, electron or atomic force microscopy for microstructure and aggregation state (Pyrgiotakis et al., 2014; Pyrgiotakis et al., 2013); dynamic or static light scattering for particle size distribution; tunable resistive pulse sensing technology for particle size and charge (Pal et al., 2014); microelectrophoresis for particle charge; and, 
chromatography, mass spectrometry, or NMR for particle composition.

However, the analysis of the properties of iENMs dispersed in complex food matrices or GI fluids is usually much more challenging (Bellmann et al., 2015; Lopez-Serrano et al., 2014; Singh et al., 2014; Szakal et al., 2014a). Food matrices or GI fluids often contain a complicated mixture of particles and polymers that may have dimensions that overlap with those of the iENMs being studied. This often means that it is difficult to determine the particle size distribution or aggregation state of the nanoparticles using conventional light scattering or microscopy methods since it is difficult to distinguish one type of particle from another. This challenge may be overcome using a number of approaches (Grieger et al., 2016; McClements and McClements, 2016; Szakal et al., 2014b). First, it may be possible to isolate the iENMs from the other particulate matter in the system using selective digestion, filtration, or centrifugation methods. However, one must be careful not to alter the properties of the iENMs being studied using these approaches. Second, it may be possible to discriminate the different types of particles in a system using selective staining methods, e.g., using colored, fluorescent, or radioactive probes. These techniques may enable one to determine the specific location of iENMs in a system and the type of substances that they tend to associate with. Similar problems arise with measurements of the interfacial composition or electrical charge of nanoparticles in complex foods or GIT fluids. The charge on pristine nanoparticles suspended in simple aqueous liquids (e.g., cell culture media) can simply be measured by placing them within a particle electrophoresis instrument (such as a zeta potential analyzer). However, it is difficult to determine the charge on the nanoparticles when they are dispersed within a complex fluid that contains many different types of particles and polymers since they all contribute to the measured electrophoretic signal. Again, it may be possible to isolate the nanoparticles from the other types 
of particulate matter in the sample prior to analysis, but one must be careful not to alter the interfacial composition during this process.

\subsection{Ingested ENM Toxicity}

Despite the large and growing number of ENMs used in agri-food products, nanotoxicology research and hazard assessment of iENMs lags behind that for other routes of exposure (e.g., inhalation, dermal). While evidence of toxicity associated with iENMs continues to grow, several critical knowledge gaps exist, preventing regulators and industry from assessing the potential health risks. These knowledge gaps include:1) uncertain human exposure data; 2) limited in vivo biokinetic and toxicological studies; and 3) lack of understanding of physicochemical ENM transformations within complex food matrices and within the GIT and their effect on bioactivity. These knowledge gaps must be addressed to develop the necessary screening strategies for hazard assessment, and to help industry design safer iENMs and food products.

Although the potential toxicity of some metal oxide ENMs with substantial ingestion exposure risk have been studied, most studies have focused on inhalation and dermal exposures, or employed in vitro methods using pristine ENMs, thus ignoring important transformations of iENMs resulting from interactions with the food matrix and conditions of the GIT (Wang et al., 2013). In addition, only a few studies have investigated in vivo toxicity of iENMs. Among these, studies of Ag nanoparticles are the most common, but these have often led to either conflicting or inconclusive results (Cha et al., 2008; Jeong et al., 2010; Kim et al., 2010; Kulthong et al., 2012; Park et al., 2010; Zhang et al., 2013). A part of the problem at this early stage in the study of the GI fate of ingested ENMs, is that the few sporadic studies in the literature vary widely in terms of ENMs tested, experimental models used, and endpoints examined. For example, Cha et al. reported liver inflammation and increased apoptosis in liver cells, as well as alterations in 
expression of genes regulating apoptosis and inflammation in mice directly fed a single $2.5 \mathrm{~g}$ bolus of Ag nanoparticles (Cha et al., 2008). On the other hand, Kim et al. reported only mild dose-dependent hepatotoxicity in rats fed $\geq 125 \mathrm{mg} / \mathrm{kg}$-day for 90 days (Kim et al., 2010). Although both of these studies are consistent with a potential hazard for liver toxicity resulting from Ag ENM ingestion, the large differences in treatment protocols and experimental models make cohesive conclusions difficult.

In the case of ingested metal oxide ENMs, the in vivo toxicology literature is even more sparse. Nevertheless, as with Ag, early indications suggest significant potential for toxicity. For example, $\mathrm{TiO}_{2}$ nanoparticles were reported to have a variety of toxic effects within the GIT (Bu et al., 2010; Nogueira et al., 2012) and to enter the systemic circulation, accumulate and cause inflammation and oxidative damage in the liver, kidney and spleen (Cui et al., 2011; Duan et al., 2010; Gui et al., 2011; Sycheva et al., 2011). It should be pointed out that these studies focused on effects of $\mathrm{TiO} 2$ nanoparticle ingestion, as distinct from GRAS forms of $\mathrm{TiO} 2$, and that although nano-scale particles have been found in GRAS materials, the majority of particles are in the micron-size range (Athinarayanan et al., 2015). Ingested $\mathrm{ZnO}$ nanoparticles were reported to undergo size-dependent intestinal absorption with accumulation in multiple organs and damage to liver and pancreas (Baek et al., 2012; Choi et al., 2015; Esmaeillou et al., 2013; Li et al., 2012; Seok et al., 2013). Ingested $\mathrm{SiO}_{2}$ ENMs caused low-level hepatotoxicity in rats following a10-week exposure period (So et al., 2008).

In addition, whereas at least a small number of studies of direct toxicity of ingested ENMs are emerging, no studies of iENM toxicity to date have employed animal models of human GIT diseases (e.g. colitis), which could reveal potential human toxicity that would remain masked in healthy animals (Dixit and Boelsterli, 2007). Likewise, while growing evidence continues to 
emphasize the critical role of the gut microbiome and its role in overall health (Consortium, 2012; Pflughoeft and Versalovic, 2012; Theriot et al., 2014; Turnbaugh et al., 2009; Weir et al., 2013), potential effects of iENMs on the gut microbiome remain largely unstudied (Bergin and Witzmann, 2013; Wilding et al., 2016; Williams et al., 2015).

Another almost entirely neglected aspect of iENM toxicological characterization is assessment of the complex effects of food matrix and GIT conditions on ENM properties (Blasco and Picó, 2011; Wang, Du, Song and Chen, 2013). As detailed above, the resulting changes to surface chemistry, agglomeration state, and biocorona of iENMs can have profound effects on their absorption, accumulation, biodistribution, and toxicity (Bouwmeester et al., 2009; Ensign et al., 2012; Frohlich and Roblegg, 2012; Powell et al., 2010). Most in vitro studies of iENM fate and toxicity have ignored these interactions, employing pristine ENMs suspended in culture media (Esch et al., 2014; Faust et al., 2014; Natarajan et al., 2015), often leading to erroneous conclusions (Gerloff et al., 2013). As discussed above, what is needed is development of in vitro and in vivo methods for studying transformations of iENMs in the GIT, and identifying structure activity relationships that influence absorption and accumulation. Methods such as simulated GIT models that include mouth, stomach, and small intestine phases that mimic the fluid compositions, incubation times, and flow/pressure conditions of the GIT are crucial for assessing ENM transformations and interactions with food matrices (Arroyo-Maya and McClements, 2016; Cho et al., 2014; Lopez-Pena et al., 2016; Mun et al., 2007; Mun et al., 2006; Ozturk et al., 2015; Park et al., 2007; Qiu et al., 2015; Sandra et al., 2008; Yao et al., 2013; Yao et al., 2015a; Yao et al., 2014; Zou et al., 2015a; Zou et al., 2015b). In future work, it may be useful to employ the newly developing "omic" approaches to better understand the potential toxicity of nanoparticles, e.g., metabolomics, proteomics, and transcriptomics. 
Finally, although animal studies are considered critical for hazard assessment, given the variety of iENMs, compounded by the multiplicity of possible food matrices, all of which can modulate uptake and toxicity, comprehensive animal testing of all iENMs would be extremely laborious and costly. Instead, a validated, tiered testing strategy, including in vitro, in vivo, and even in silico approaches, consistent with the US National Research Council's prescribed paradigm shift toward alternative testing strategies in Toxicity Testing in the 21st Century: A Vision and a Strategy (Krewski et al., 2010) needs to be developed.

\section{Regulatory considerations}

Regulatory agencies in the US and EU have published policies and guidance on the use of nanomaterials in food (EFSA, 2011; FDA, 2014a; FDA, 2014b; Hamburg, 2012). The combination of scientific uncertainty and lack of regulatory experience has led to a situation where agencies have not yet adopted a definition of nanomaterials, nor specific processes for managing regulatory approvals for nanoscale forms of food ingredients and additives. The Food and Drug Administration (FDA), ESFA and other key international food safety agencies have collectively adopted a "case-by-case" approach to evaluation of the safety of nanomaterials in food applications. In the U.S. in lieu of a definition, FDA has developed guidance on how to assess whether a new process is a product of nanotechnology, and if so, what additional types of testing may be appropriate. The most significant change is the recommendation to measure a range of physical and chemical properties in advance of, during, and following exposure during dose response and other toxicological assays to assess the transformations that might occur in biological media and understand the characteristics of the nanoscale material.

FDA's guidance is similar to that of the European Food Safety Authority (EFSA) in 
recommending each physical and chemical characteristic be measured by two analytical methods due to measurement error, as well as in key experimental stages. EFSA further recommends specific types of testing depending on the persistence of the nano-form of the substance in the food article, or in the body following ingestion. The recommendation for testing of the nanospecific form is determined by whether the nano-form persists into the GI tract. Otherwise safety may be determined by testing of conventional materials.

The guidance documents indicate that regulatory agencies are concerned about potential impacts of smaller particles affecting dynamics and reactions within the GI tract, differential uptake across the gut lumen, antimicrobial effects, translocation into other organs and higher potency and/or bioavailability than conventional food additives or ingredients.

\section{Conclusions}

There is increasing concern about the potential adverse effects of iENMs on human health and wellbeing, as well as on the environment. Consequently, there is a need to understand the relationship between pristine ENM intrinsic properties , their physico-chemical transformations across the GIT and GI fate, and their potential toxicity. Many previous studies have used relatively simple cellular model systems where pristine iENMs are introduced into cell culture models to study their absorption and toxicity. However, these models ignore ENM property transformations that occur within foods and within the GIT. There may be pronounced changes in the interfacial properties, composition, charge, size, and aggregation state of ENMs as they pass through the GIT, which are influenced by the type of food that they are ingested with. It is therefore important to develop sophisticated in vitro model systems to take into account food matrix and GIT effects on the properties of ENMs under simulated GI conditions. The use of 
these models will lead to a better understanding and prediction of the behavior of iENMs within the human body, and therefore help establish their potential toxic effects. The current methods used to characterize pristine iENMs or their aqueous or simple culture media suspensions are not adequate to be used in such complex biological media and there is a need to develop new characterization methods suitable for complex media. Furthermore, there is a need to develop a validated, tiered testing strategy, including in vitro, in vivo and even in silico approaches to assess potential risks from iENMs.

\section{Funding information}

This material was partly based upon work supported by the Cooperative State Research, Extension, Education Service, USDA, Massachusetts Agricultural Experiment Station (MAS00491) and USDA, NRI Grants (2013-03795 and 2014-67021). This research project was supported by Harvard-NIEHS Nanosafety Center grant (1U24ES026946).

\section{References}

Abdul Khalil, H. P., Saurabh, C. K., Adnan, A. S., Nurul Fazita, M. R., Syakir, M. I., Davoudpour, Y., Rafatullah, M., Abdullah, C. K., K., H. M., and Dungani, R. (2016). A review on chitosan-cellulose blends and nanocellulose reinforced chitosan biocomposites: Properties and their applications. Carbohydrate polymers 150, 216-26, 10.1016/j.carbpol.2016.05.028.

Acosta, E. (2009). Bioavailability of nanoparticles in nutrient and nutraceutical delivery. Current Opinion in Colloid \& Interface Science 14(1), 3-15, 10.1016/j.cocis.2008.01.002. 
Akhtar, J., Khan, A. A., Ali, Z., Haider, R., and Shahar Yar, M. (2016). Structure-activity relationship (SAR) study and design strategies of nitrogen-containing heterocyclic moieties for their anticancer activities. European journal of medicinal chemistry 125, 143-189, 10.1016/j.ejmech.2016.09.023.

Arroyo-Maya, I. J., and McClements, D. J. (2016). Application of ITC in foods: A powerful tool for understanding the gastrointestinal fate of lipophilic compounds. Biochimica et biophysica acta 1860(5), 1026-35, 10.1016/j.bbagen.2015.10.001.

Athinarayanan, J., Alshatwi, A. A., Periasamy, V. S., and Al-Warthan, A. A. (2015). Identification of nanoscale ingredients in commercial food products and their induction of mitochondrially mediated cytotoxic effects on human mesenchymal stem cells. Journal of food science $\mathbf{8 0}(2)$, N459-64, 10.1111/1750-3841.12760.

Athinarayanan, J., Periasamy, V. S., Alsaif, M. A., Al-Warthan, A. A., and Alshatwi, A. A. (2014). Presence of nanosilica (E551) in commercial food products: TNF-mediated oxidative stress and altered cell cycle progression in human lung fibroblast cells. Cell biology and toxicology 30(2), 89-100, 10.1007/s10565-014-9271-8.

Aulin, C., Salazar-Alvarez, G., and Lindstrom, T. (2012). High strength, flexible and transparent nanofibrillated cellulose-nanoclay biohybrid films with tunable oxygen and water vapor permeability. Nanoscale 4(20), 6622-8, 10.1039/c2nr31726e. 
Axson, J. L., Stark, D. I., Bondy, A. L., Capracotta, S. S., Maynard, A. D., Philbert, M. A., Bergin, I. L., and Ault, A. P. (2015). Rapid Kinetics of Size and pH-Dependent Dissolution and Aggregation of Silver Nanoparticles in Simulated Gastric Fluid. The Journal of Physical Chemistry C 119(35), 20632-20641, 10.1021/acs.jpcc.5b03634.

Baek, M., Chung, H. E., Yu, J., Lee, J. A., Kim, T. H., Oh, J. M., Lee, W. J., Paek, S. M., Lee, J. K., Jeong, J., Choy, J. H., and Choi, S. J. (2012). Pharmacokinetics, tissue distribution, and excretion of zinc oxide nanoparticles. International journal of nanomedicine 7, 3081-97, 10.2147/ijn.s32593.

Bellmann, S., Carlander, D., Fasano, A., Momcilovic, D., Scimeca, J. A., Waldman, W. J., Gombau, L., Tsytsikova, L., Canady, R., Pereira, D. I. A., and Lefebvre, D. E. (2015). Mammalian gastrointestinal tract parameters modulating the integrity, surface properties, and absorption of food-relevant nanomaterials. Wiley Interdisciplinary Reviews-Nanomedicine and Nanobiotechnology 7(5), 609-622, 10.1002/wnan.1333.

Bergin, I. L., and Witzmann, F. A. (2013). Nanoparticle toxicity by the gastrointestinal route: evidence and knowledge gaps. International journal of biomedical nanoscience and nanotechnology 3(1-2), 10.1504/ijbnn.2013.054515.

Blasco, C., and Picó, Y. (2011). Determining nanomaterials in food. TrAC Trends in Analytical Chemistry 30(1), 84-99, http://dx.doi.org/10.1016/j.trac.2010.08.010. 
Blijdenstein, T. B. J., van der Linden, E., van Vliet, T., and van Aken, G. A. (2004). Scaling behavior of delayed demixing, rheology, and microstructure of emulsions flocculated by depletion and bridging. Langmuir : the ACS journal of surfaces and colloids 20(26), 1132111328.

Bonnaire, L., Sandra, S., Helgason, T., Decker, E. A., Weiss, J., and McClements, D. J. (2008). Influence of lipid physical state on the in vitro digestibility of emulsified lipids. Journal of agricultural and food chemistry 56(10), 3791-3797, 10.1021/jf800159e.

Bouwmeester, H., Dekkers, S., Noordam, M. Y., Hagens, W. I., Bulder, A. S., de Heer, C., ten Voorde, S., Wijnhoven, S. W. P., Marvin, H. J. P., and Sips, A. (2009). Review of health safety aspects of nanotechnologies in food production. Regulatory Toxicology and Pharmacology 53(1), 52-62, 10.1016/j.yrtph.2008.10.008.

Brasiliense, V., Patel, A. N., Martinez-Marrades, A., Shi, J., Chen, Y., Combellas, C., Tessier, G., and Kanoufi, F. (2016). Correlated Electrochemical and Optical Detection Reveals the Chemical Reactivity of Individual Silver Nanoparticles. Journal of the American Chemical Society 138(10), 3478-83, 10.1021/jacs.5b13217.

Bu, Q., Yan, G., Deng, P., Peng, F., Lin, H., Xu, Y., Cao, Z., Zhou, T., Xue, A., Wang, Y., Cen, X., and Zhao, Y. L. (2010). NMR-based metabonomic study of the sub-acute toxicity of titanium dioxide nanoparticles in rats after oral administration. Nanotechnology 21(12), 125105, 
$10.1088 / 0957-4484 / 21 / 12 / 125105$.

Bugusu, B., Mejia, C., Magnuson, B., and Tafazoli, S. (2009). Global Regulatory Policies on Food Nanotechnology. Food Technology 63(5), 24-28.

Buzea, C., Pacheco, II, and Robbie, K. (2007). Nanomaterials and nanoparticles: Sources and toxicity. Biointerphases 2(4), MR17-MR71, 10.1116/1.2815690.

Cha, K., Hong, H. W., Choi, Y. G., Lee, M. J., Park, J. H., Chae, H. K., Ryu, G., and Myung, H. (2008). Comparison of acute responses of mice livers to short-term exposure to nano-sized or micro-sized silver particles. Biotechnol Lett 30(11), 1893-9, 10.1007/s10529-008-9786-2.

Cho, H. T., Salvia-Trujillo, L., Kim, J., Park, Y., Xiao, H., and McClements, D. J. (2014). Droplet size and composition of nutraceutical nanoemulsions influences bioavailability of long chain fatty acids and Coenzyme Q10. Food Chem 156, 117-22, 10.1016/j.foodchem.2014.01.084.

Choi, J., Kim, H., Kim, P., Jo, E., Kim, H. M., Lee, M. Y., Jin, S. M., and Park, K. (2015). Toxicity of zinc oxide nanoparticles in rats treated by two different routes: single intravenous injection and single oral administration. Journal of toxicology and environmental health. Part A 78(4), 226-43, 10.1080/15287394.2014.949949.

Cohen, J., Deloid, G., Pyrgiotakis, G., and Demokritou, P. (2013). Interactions of engineered nanomaterials in physiological media and implications for in vitro dosimetry. Nanotoxicology 
7(4), 417-31, 10.3109/17435390.2012.666576.

Cohen, J. M., DeLoid, G. M., and Demokritou, P. (2015). A critical review of in vitro dosimetry for engineered nanomaterials. Nanomedicine (London, England) doi: 10.2217/nnm.15.129, 10.2217/nnm.15.129.

Cohen, J. M., Derk, R., Wang, L., Godleski, J., Kobzik, L., Brain, J., and Demokritou, P. (2014a). Tracking translocation of industrially relevant engineered nanomaterials (ENMs) across alveolar epithelial monolayers in vitro. Nanotoxicology 8 Suppl 1, 216-25, 10.3109/17435390.2013.879612.

Cohen, J. M., Teeguarden, J. G., and Demokritou, P. (2014b). An integrated approach for the in vitro dosimetry of engineered nanomaterials. Particle and fibre toxicology 11, 20, 10.1186/17438977-11-20.

Consortium, H. M. P. (2012). Structure, function and diversity of the healthy human microbiome. Nature 486(7402), 207-14, 10.1038/nature11234.

Contado, C. (2015). Nanomaterials in consumer products: a challenging analytical problem. Frontiers in chemistry 3, 48, 10.3389/fchem.2015.00048.

Cordomi, A., Fourmy, D., and Tikhonova, I. G. (2016). Gut hormone GPCRs: structure, function, drug discovery. Current opinion in pharmacology 31, 63-67, 10.1016/j.coph.2016.09.001. 
Costa, S. S., Druzian, J. I., Machado, B. A., de Souza, C. O., and Guimaraes, A. G. (2014). Bifunctional biobased packing of the cassava starch, glycerol, licuri nanocellulose and red propolis. PloS one 9(11), e112554, 10.1371/journal.pone.0112554.

Cui, Y., Liu, H., Zhou, M., Duan, Y., Li, N., Gong, X., Hu, R., Hong, M., and Hong, F. (2011). Signaling pathway of inflammatory responses in the mouse liver caused by $\mathrm{TiO} 2$ nanoparticles. Journal of biomedical materials research. Part A 96(1), 221-9, 10.1002/jbm.a.32976.

Davidson, D. C., Derk, R., He, X., Stueckle, T. A., Cohen, J., Pirela, S. V., Demokritou, P., Rojanasakul, Y., and Wang, L. (2016). Direct stimulation of human fibroblasts by nCeO2 in vitro is attenuated with an amorphous silica coating. Particle and fibre toxicology 13(1), 23, 10.1186/s12989-016-0134-8.

de Hoog, E. H. A., Prinz, J. F., Huntjens, L., Dresselhuis, D. M., and van Aken, G. A. (2006). Lubrication of oral surfaces by food emulsions: the importance of surface characteristics. Journal of food science 71(7), E337-E341.

Dehnad, D., Mirzaei, H., Emam-Djomeh, Z., Jafari, S. M., and Dadashi, S. (2014). Thermal and antimicrobial properties of chitosan-nanocellulose films for extending shelf life of ground meat. Carbohydrate polymers 109, 148-54, 10.1016/j.carbpol.2014.03.063.

Dekkers, S., Krystek, P., Peters, R. J. B., Lankveld, D. P. K., Bokkers, B. G. H., van Hoeven- 
Arentzen, P. H., Bouwmeester, H., and Oomen, A. G. (2011). Presence and risks of nanosilica in food products. Nanotoxicology 5(3), 393-405, 10.3109/17435390.2010.519836.

DeLoid, G., Cohen, J. M., Darrah, T., Derk, R., Rojanasakul, L., Pyrgiotakis, G., Wohlleben, W., and Demokritou, P. (2014). Estimating the effective density of engineered nanomaterials for in vitro dosimetry. Nature communications 5, 3514, 10.1038/ncomms4514.

DeLoid, G. M., Cohen, J. M., Pyrgiotakis, G., Pirela, S. V., Pal, A., Liu, J., Srebric, J., and Demokritou, P. (2015). Advanced computational modeling for in vitro nanomaterial dosimetry. Particle and fibre toxicology 12, 32, 10.1186/s12989-015-0109-1.

Dixit, R., and Boelsterli, U. A. (2007). Healthy animals and animal models of human disease(s) in safety assessment of human pharmaceuticals, including therapeutic antibodies. Drug discovery today 12(7-8), 336-42, 10.1016/j.drudis.2007.02.018.

Duan, Y., Liu, J., Ma, L., Li, N., Liu, H., Wang, J., Zheng, L., Liu, C., Wang, X., Zhao, X., Yan, J., Wang, S., Wang, H., Zhang, X., and Hong, F. (2010). Toxicological characteristics of nanoparticulate anatase titanium dioxide in mice. Biomaterials 31(5), 894-9, 10.1016/j.biomaterials.2009.10.003.

EFSA (2011). Scientific Opinion on Guidance on the risk assessment of the application of nanoscience and nanotechnologies in the food and feed chain. EFSA Journal 9(5), 36, 10.2903/j.efsa.2011.2140. 
El-Wakil, N. A., Hassan, E. A., Abou-Zeid, R. E., and Dufresne, A. (2015). Development of wheat gluten/nanocellulose/titanium dioxide nanocomposites for active food packaging. Carbohydrate polymers 124, 337-46, 10.1016/j.carbpol.2015.01.076.

Ensign, L. M., Cone, R., and Hanes, J. (2012). Oral drug delivery with polymeric nanoparticles: the gastrointestinal mucus barriers. Advanced drug delivery reviews 64(6), 557-70, 10.1016/j.addr.2011.12.009.

Esch, M. B., Mahler, G. J., Stokol, T., and Shuler, M. L. (2014). Body-on-a-chip simulation with gastrointestinal tract and liver tissues suggests that ingested nanoparticles have the potential to cause liver injury. Lab on a chip 14(16), 3081-92, 10.1039/c4lc00371c.

Esmaeillou, M., Moharamnejad, M., Hsankhani, R., Tehrani, A. A., and Maadi, H. (2013). Toxicity of $\mathrm{ZnO}$ nanoparticles in healthy adult mice. Environmental toxicology and pharmacology 35(1), 67-71, 10.1016/j.etap.2012.11.003.

Faust, J. J., Doudrick, K., Yang, Y., Westerhoff, P., and Capco, D. G. (2014). Food grade titanium dioxide disrupts intestinal brush border microvilli in vitro independent of sedimentation. Cell biology and toxicology 30(3), 169-88, 10.1007/s10565-014-9278-1.

FDA (2014a). Guidance for Industry: Assessing the Effects of Significant Manufacturing Process Changes, Including Emerging Technologies, on the Safety and Regulatory Status of 
Food Ingredients and Food Contact Substances, Including Food Ingredients that are Color Additives

FDA (2014b). Guidance for Industry: Considering Whether an FDA-Regulated Product Involves the Application of Nanotechnology. In (FDA, Ed.) Eds.)

Frohlich, E., and Roblegg, E. (2012). Models for oral uptake of nanoparticles in consumer products. Toxicology 291(1-3), 10-7, 10.1016/j.tox.2011.11.004.

Gerloff, K., Pereira, D. I., Faria, N., Boots, A. W., Kolling, J., Forster, I., Albrecht, C., Powell, J. J., and Schins, R. P. (2013). Influence of simulated gastrointestinal conditions on particleinduced cytotoxicity and interleukin-8 regulation in differentiated and undifferentiated Caco-2 cells. Nanotoxicology 7(4), 353-66, 10.3109/17435390.2012.662249.

Golding, M., Wooster, T. J., Day, L., Xu, M., Lundin, L., Keogh, J., and Clifton, P. (2011). Impact of gastric structuring on the lipolysis of emulsified lipids. Soft Matter 7(7), 3513-3523, $10.1039 / \mathrm{c} 0 \mathrm{sm} 01227 \mathrm{k}$.

Grafe, M., Donner, E., Collins, R. N., and Lombi, E. (2014). Speciation of metal(loid)s in environmental samples by X-ray absorption spectroscopy: a critical review. Analytica chimica acta 822, 1-22, 10.1016/j.aca.2014.02.044.

Grieger, K. D., Harrington, J., and Mortensen, N. (2016). Prioritizing research needs for 
analytical techniques suited for engineered nanomaterials in food. Trends in Food Science \& Technology 50, 219-229, http://dx.doi.org/10.1016/j.tifs.2016.02.004.

Gui, S., Zhang, Z., Zheng, L., Cui, Y., Liu, X., Li, N., Sang, X., Sun, Q., Gao, G., Cheng, Z., Cheng, J., Wang, L., Tang, M., and Hong, F. (2011). Molecular mechanism of kidney injury of mice caused by exposure to titanium dioxide nanoparticles. Journal of hazardous materials $\mathbf{1 9 5}$, 365-70, 10.1016/j.jhazmat.2011.08.055.

Gwartney, E. A., Larick, D. K., and Foegeding, E. A. (2004). Sensory texture and mechanical properties of stranded and particulate whey protein emulsion gels. Journal of food science 69(9), S333-S339.

Hajipour, M. J., Fromm, K. M., Ashkarran, A. A., Jimenez de Aberasturi, D., Ruiz de Larramendi, I., Rojo, T., Serpooshan, V., Parak, W. J., and Mahmoudi, M. (2012). Antibacterial properties of nanoparticles. Trends in Biotechnology 30(10), 499-511, 10.1016/j.tibtech.2012.06.004.

Hamburg, M. A. (2012). Science and regulation. FDA's approach to regulation of products of nanotechnology. Science (New York, N.Y.) 336(6079), 299-300, 10.1126/science.1205441.

Holt, C., de Kruif, C. G., Tuinier, R., and Timmins, P. A. (2003). Substructure of bovine casein micelles by small-angle X-ray and neutron scattering. Colloids and Surfaces a-Physicochemical and Engineering Aspects 213(2-3), 275-284, 10.1016/s0927-7757(02)00520-4. 
Jeong, G. N., Jo, U. B., Ryu, H. Y., Kim, Y. S., Song, K. S., and Yu, I. J. (2010). Histochemical study of intestinal mucins after administration of silver nanoparticles in Sprague-Dawley rats. Archives of toxicology 84(1), 63-9, 10.1007/s00204-009-0469-0.

Kelly, P. M., Aberg, C., Polo, E., O'Connell, A., Cookman, J., Fallon, J., Krpetic, Z., and Dawson, K. A. (2015). Mapping protein binding sites on the biomolecular corona of nanoparticles. Nature nanotechnology 10(5), 472-9, 10.1038/nnano.2015.47.

Khalili Fard, J., Jafari, S., and Eghbal, M. A. (2015). A Review of Molecular Mechanisms Involved in Toxicity of Nanoparticles. Advanced pharmaceutical bulletin 5(4), 447-54, 10.15171/apb.2015.061.

Kim, Y. S., Song, M. Y., Park, J. D., Song, K. S., Ryu, H. R., Chung, Y. H., Chang, H. K., Lee, J. H., Oh, K. H., Kelman, B. J., Hwang, I. K., and Yu, I. J. (2010). Subchronic oral toxicity of silver nanoparticles. Particle and fibre toxicology 7, 20, 10.1186/1743-8977-7-20.

Konduru, N. V., Jimenez, R. J., Swami, A., Friend, S., Castranova, V., Demokritou, P., Brain, J. D., and Molina, R. M. (2015). Silica coating influences the corona and biokinetics of cerium oxide nanoparticles. Particle and fibre toxicology 12, 31, 10.1186/s12989-015-0106-4.

Konduru, N. V., Murdaugh, K. M., Sotiriou, G. A., Donaghey, T. C., Demokritou, P., Brain, J. D., and Molina, R. M. (2014). Bioavailability, distribution and clearance of tracheally-instilled and 
gavaged uncoated or silica-coated zinc oxide nanoparticles. Particle and fibre toxicology 11, 44, 10.1186/s12989-014-0044-6.

Konduru, N. V., Murdaugh, K. M., Swami, A., Jimenez, R. J., Donaghey, T. C., Demokritou, P., Brain, J. D., and Molina, R. M. (2016). Surface modification of zinc oxide nanoparticles with amorphous silica alters their fate in the circulation. Nanotoxicology 10(6), 720-7, $10.3109 / 17435390.2015 .1113322$.

Krewski, D., Acosta, D., Jr., Andersen, M., Anderson, H., Bailar, J. C., 3rd, Boekelheide, K., Brent, R., Charnley, G., Cheung, V. G., Green, S., Jr., Kelsey, K. T., Kerkvliet, N. I., Li, A. A., McCray, L., Meyer, O., Patterson, R. D., Pennie, W., Scala, R. A., Solomon, G. M., Stephens, M., Yager, J., and Zeise, L. (2010). Toxicity testing in the 21 st century: a vision and a strategy. Journal of toxicology and environmental health. Part B, Critical reviews 13(2-4), 51-138, 10.1080/10937404.2010.483176.

Kulthong, K., Maniratanachote, R., Kobayashi, Y., Fukami, T., and Yokoi, T. (2012). Effects of silver nanoparticles on rat hepatic cytochrome P450 enzyme activity. Xenobiotica; the fate of foreign compounds in biological systems 42(9), 854-62, 10.3109/00498254.2012.670312.

Kuzmin, A., and Chaboy, J. (2014). EXAFS and XANES analysis of oxides at the nanoscale. IUCrJ 1(Pt 6), 571-89, 10.1107/s2052252514021101.

Laborda, F., Bolea, E., Cepria, G., Gomez, M. T., Jimenez, M. S., Perez-Arantegui, J., and 
Castillo, J. R. (2016). Detection, characterization and quantification of inorganic engineered nanomaterials: A review of techniques and methodological approaches for the analysis of complex samples. Analytica chimica acta 904, 10-32, 10.1016/j.aca.2015.11.008.

Li, C. H., Shen, C. C., Cheng, Y. W., Huang, S. H., Wu, C. C., Kao, C. C., Liao, J. W., and Kang, J. J. (2012). Organ biodistribution, clearance, and genotoxicity of orally administered zinc oxide nanoparticles in mice. Nanotoxicology 6(7), 746-56, 10.3109/17435390.2011.620717.

Li, Y., Le Maux, S., Xiao, H., and McClements, D. J. (2009). Emulsion-Based Delivery Systems for Tributyrin, a Potential Colon Cancer Preventative Agent. Journal of agricultural and food chemistry 57(19), 9243-9249, 10.1021/jf901836f.

Lim, J. H., Sisco, P., Mudalige, T. K., Sanchez-Pomales, G., Howard, P. C., and Linder, S. W. (2015). Detection and characterization of $\mathrm{SiO} 2$ and $\mathrm{TiO} 2$ nanostructures in dietary supplements. Journal of agricultural and food chemistry 63(12), 3144-52, 10.1021/acs.jafc.5b00392.

Liu, R., France, B., George, S., Rallo, R., Zhang, H., Xia, T., Nel, A. E., Bradley, K., and Cohen, Y. (2014). Association rule mining of cellular responses induced by metal and metal oxide nanoparticles. The Analyst 139(5), 943-53, 10.1039/c3an01409f.

Liu, R., Zhang, H. Y., Ji, Z. X., Rallo, R., Xia, T., Chang, C. H., Nel, A., and Cohen, Y. (2013). Development of structure-activity relationship for metal oxide nanoparticles. Nanoscale 5(12), 5644-53, 10.1039/c3nr01533e. 
Livney, Y. D. (2010). Milk proteins as vehicles for bioactives. Current Opinion in Colloid \& Interface Science 15(1-2), 73-83, 10.1016/j.cocis.2009.11.002.

Livney, Y. D. (2015). Nanostructured delivery systems in food: latest developments and potential future directions. Current Opinion in Food Science 3, 125-135, 10.1016/j.cofs.2015.06.010.

Lopez-Pena, C. L., Zheng, B., Sela, D. A., Decker, E. A., Xiao, H., and McClements, D. J. (2016). Impact of epsilon-polylysine and pectin on the potential gastrointestinal fate of emulsified lipids: In vitro mouth, stomach and small intestine model. Food Chem 192, 857-64, 10.1016/j.foodchem.2015.07.054.

Lopez-Serrano, A., Olivas, R. M., Landaluze, J. S., and Camara, C. (2014). Nanoparticles: a global vision. Characterization, separation, and quantification methods. Potential environmental and health impact. Analytical Methods 6(1), 38-56, 10.1039/c3ay40517f.

Lu, X., Miousse, I. R., Pirela, S. V., Melnyk, S., Koturbash, I., and Demokritou, P. (2016a). Short-term exposure to engineered nanomaterials affects cellular epigenome. Nanotoxicology 10(2), 140-50, 10.3109/17435390.2015.1025115.

Lu, X., Miousse, I. R., Pirela, S. V., Moore, J. K., Melnyk, S., Koturbash, I., and Demokritou, P. (2016b). In vivo epigenetic effects induced by engineered nanomaterials: A case study of copper oxide and laser printer-emitted engineered nanoparticles. Nanotoxicology 10(5), 629-39, 
10.3109/17435390.2015.1108473.

Lundqvist, M., Stigler, J., Cedervall, T., Berggard, T., Flanagan, M. B., Lynch, I., Elia, G., and Dawson, K. (2011). The evolution of the protein corona around nanoparticles: a test study. ACS nano 5(9), 7503-9, 10.1021/nn202458g.

Ma, J., Mercer, R. R., Barger, M., Schwegler-Berry, D., Cohen, J. M., Demokritou, P., and Castranova, V. (2015). Effects of amorphous silica coating on cerium oxide nanoparticles induced pulmonary responses. Toxicology and applied pharmacology 288(1), 63-73, 10.1016/j.taap.2015.07.012.

Ma, X., Wang, Q., Rossi, L., Ebbs, S. D., and White, J. C. (2016). Multigenerational exposure to cerium oxide nanoparticles: Physiological and biochemical analysis reveals transmissible changes in rapid cycling Brassica rapa. NanoImpact 1, 46-54, http://dx.doi.org/10.1016/j.impact.2016.04.001.

Magnuson, B. A., Jonaitis, T. S., and Card, J. W. (2011). A Brief Review of the Occurrence, Use, and Safety of Food-Related Nanomaterials. Journal of food science 76(6), R126-R133, 10.1111/j.1750-3841.2011.02170.x.

Malone, M. E., Appelqvist, I. A. M., and Norton, I. T. (2003a). Oral behaviour of food hydrocolloids and emulsions. Part 1. Lubrication and deposition considerations. Food Hydrocolloids 17(6), 763-773. 
Malone, M. E., Appelqvist, I. A. M., and Norton, I. T. (2003b). Oral behaviour of food hydrocolloids and emulsions. Part 2. Taste and aroma release. Food Hydrocolloids 17(6), 775784.

McClements, D. J. (2011). Edible nanoemulsions: fabrication, properties, and functional performance. Soft Matter 7(6), 2297-2316, 10.1039/c0sm00549e.

McClements, D. J. (2012). Advances in fabrication of emulsions with enhanced functionality using structural design principles. Current Opinion in Colloid \& Interface Science 17(5), 235 245.

McClements, D. J. (2014). Nanoparticle- and Microparticle-based Delivery Systems:

Encapsulation, Protection and Release of Active Compounds. CRC Press, Boca Raton, FL.

McClements, D. J., Li, F., and Xiao, H. (2015). The nutraceutical bioavailability classification scheme: classifying nutraceuticals according to factors limiting their oral bioavailability. Annual Review of Food Science and Technology 6(1), 299-327, 10.1146/annurev-food-032814-014043.

McClements, J., and McClements, D. J. (2016). Standardization of Nanoparticle Characterization: Methods for Testing Properties, Stability, and Functionality of Edible Nanoparticles. Crit Rev Food Sci Nutr 56(8), 1334-62, 10.1080/10408398.2014.970267. 
Monopoli, M. P., Walczyk, D., Campbell, A., Elia, G., Lynch, I., Baldelli Bombelli, F., and Dawson, K. A. (2011a). Physical-Chemical Aspects of Protein Corona: Relevance to in Vitro and in Vivo Biological Impacts of Nanoparticles. Journal of the American Chemical Society 133(8), 2525-2534, 10.1021/ja107583h.

Monopoli, M. P., Walczyk, D., Campbell, A., Elia, G., Lynch, I., Bombelli, F. B., and Dawson, K. A. (2011b). Physical-chemical aspects of protein corona: relevance to in vitro and in vivo biological impacts of nanoparticles. Journal of the American Chemical Society 133(8), 2525-34, $10.1021 /$ ja107583h.

Montano, M. D., Olesik, J. W., Barber, A. G., Challis, K., and Ranville, J. F. (2016). Single Particle ICP-MS: Advances toward routine analysis of nanomaterials. Analytical and bioanalytical chemistry 408(19), 5053-74, 10.1007/s00216-016-9676-8.

Monteiro, J. P., Alves, M. G., Oliveira, P. F., and Silva, B. M. (2016). Structure-Bioactivity Relationships of Methylxanthines: Trying to Make Sense of All the Promises and the Drawbacks. Molecules (Basel, Switzerland) 21(8), 10.3390/molecules21080974.

Mun, S., Decker, E. A., and McClements, D. J. (2007). Influence of emulsifier type on in vitro digestibility of lipid droplets by pancreatic lipase. Food Research International 40(6), 770-781, http://dx.doi.org/10.1016/j.foodres.2007.01.007.

Mun, S., Decker, E. A., Park, Y., Weiss, J., and McClements, D. J. (2006). Influence of Interfacial 
Composition on in Vitro Digestibility of Emulsified Lipids: Potential Mechanism for Chitosan's Ability to Inhibit Fat Digestion. Food Biophysics 1(1), 21-29, 10.1007/s11483-005-9001-0.

Natarajan, V., Wilson, C. L., Hayward, S. L., and Kidambi, S. (2015). Titanium Dioxide Nanoparticles Trigger Loss of Function and Perturbation of Mitochondrial Dynamics in Primary Hepatocytes. PloS one 10(8), e0134541, 10.1371/journal.pone.0134541.

Nogueira, C. M., de Azevedo, W. M., Dagli, M. L., Toma, S. H., Leite, A. Z., Lordello, M. L., Nishitokukado, I., Ortiz-Agostinho, C. L., Duarte, M. I., Ferreira, M. A., and Sipahi, A. M. (2012). Titanium dioxide induced inflammation in the small intestine. World journal of gastroenterology 18(34), 4729-35, 10.3748/wjg.v18.i34.4729.

Norton, J. E., Gonzalez Espinosa, Y., Watson, R. L., Spyropoulos, F., and Norton, I. T. (2015). Functional food microstructures for macronutrient release and delivery. Food \& function 6(3), $663-78,10.1039 / \mathrm{c} 4$ fo00965g.

Ozturk, B., Argin, S., Ozilgen, M., and McClements, D. J. (2015). Nanoemulsion delivery systems for oil-soluble vitamins: Influence of carrier oil type on lipid digestion and vitamin D3 bioaccessibility. Food Chem 187, 499-506, 10.1016/j.foodchem.2015.04.065.

Pal, A. K., Aalaei, I., Gadde, S., Gaines, P., Schmidt, D., Demokritou, P., and Bello, D. (2014). High resolution characterization of engineered nanomaterial dispersions in complex media using tunable resistive pulse sensing technology. ACS nano 8(9), 9003-15, 10.1021/nn502219q. 
Park, E. J., Bae, E., Yi, J., Kim, Y., Choi, K., Lee, S. H., Yoon, J., Lee, B. C., and Park, K. (2010). Repeated-dose toxicity and inflammatory responses in mice by oral administration of silver nanoparticles. Environmental toxicology and pharmacology 30(2), 162-8, 10.1016/j.etap.2010.05.004.

Park, G. Y., Mun, S., Park, Y., Rhee, S., Decker, E. A., Weiss, J., McClements, D. J., and Park, Y. (2007). Influence of encapsulation of emulsified lipids with chitosan on their in vivo digestibility. Food Chemistry 104(2), 761-767, http://dx.doi.org/10.1016/j.foodchem.2006.12.020.

Peters, R., Kramer, E., Oomen, A. G., Rivera, Z. E. H., Oegema, G., Tromp, P. C., Fokkink, R., Rietveld, A., Marvin, H. J. P., Weigel, S., Peijnenburg, A., and Bouwmeester, H. (2012). Presence of Nano-Sized Silica during In Vitro Digestion of Foods Containing Silica as a Food Additive. ACS nano 6(3), 2441-2451, 10.1021/nn204728k.

Peters, R. J., van Bemmel, G., Herrera-Rivera, Z., Helsper, H. P., Marvin, H. J., Weigel, S., Tromp, P. C., Oomen, A. G., Rietveld, A. G., and Bouwmeester, H. (2014). Characterization of titanium dioxide nanoparticles in food products: analytical methods to define nanoparticles. Journal of agricultural and food chemistry 62(27), 6285-93, 10.1021/jf5011885.

Pezzuto, A., Losasso, C., Mancin, M., Gallocchio, F., Piovesana, A., Binato, G., Gallina, A., Marangon, A., Mioni, R., Favretti, M., and Ricci, A. (2015). Food safety concerns deriving from 
the use of silver based food packaging materials. Frontiers in Microbiology 6, 10.3389/fmicb.2015.01109.

Pflughoeft, K. J., and Versalovic, J. (2012). Human microbiome in health and disease. Annual review of pathology 7, 99-122, 10.1146/annurev-pathol-011811-132421.

Pirela, S. V., Lu, X., Miousse, I., Sisler, J. D., Qian, Y., Guo, N., Koturbash, I., Castranova, V., Thomas, T., Godleski, J., and Demokritou, P. (2016a). Effects of intratracheally instilled laser printer-emitted engineered nanoparticles in a mouse model: A case study of toxicological implications from nanomaterials released during consumer use. NanoImpact 1, 1-8, 10.1016/j.impact.2015.12.001.

Pirela, S. V., Miousse, I. R., Lu, X., Castranova, V., Thomas, T., Qian, Y., Bello, D., Kobzik, L., Koturbash, I., and Demokritou, P. (2016b). Effects of Laser Printer-Emitted Engineered Nanoparticles on Cytotoxicity, Chemokine Expression, Reactive Oxygen Species, DNA Methylation, and DNA Damage: A Comprehensive in Vitro Analysis in Human Small Airway Epithelial Cells, Macrophages, and Lymphoblasts. Environmental health perspectives 124(2), 210-9, 10.1289/ehp.1409582.

Powell, J. J., Faria, N., Thomas-McKay, E., and Pele, L. C. (2010). Origin and fate of dietary nanoparticles and microparticles in the gastrointestinal tract. Journal of autoimmunity 34(3), J226-33, 10.1016/j.jaut.2009.11.006. 
Pradeep, T., and Anshup (2009). Noble metal nanoparticles for water purification: A critical review. Thin Solid Films 517(24), 6441-6478, 10.1016/j.tsf.2009.03.195.

Putz, M. V., Duda-Seiman, C., Duda-Seiman, D., Putz, A. M., Alexandrescu, I., Mernea, M., and Avram, S. (2016). Chemical Structure-Biological Activity Models for Pharmacophores' 3DInteractions. International journal of molecular sciences 17(7), 10.3390/ijms17071087.

Pyrgiotakis, G., Blattmann, C. O., and Demokritou, P. (2014). Real-Time Nanoparticle-Cell Interactions in Physiological Media by Atomic Force Microscopy. ACS sustainable chemistry \& engineering 2(7), 1681-1690, 10.1021/sc500152g.

Pyrgiotakis, G., Blattmann, C. O., Pratsinis, S., and Demokritou, P. (2013). Nanoparticlenanoparticle interactions in biological media by atomic force microscopy. Langmuir : the ACS journal of surfaces and colloids 29(36), 11385-95, 10.1021/la4019585.

Qiu, C., Zhao, M., Decker, E. A., and McClements, D. J. (2015). Influence of protein type on oxidation and digestibility of fish oil-in-water emulsions: gliadin, caseinate, and whey protein. Food Chem 175, 249-57, 10.1016/j.foodchem.2014.11.112.

Raspopov, R. V., Trushina, E. N., Gmoshinsky, I. V., and Khotimchenko, S. A. (2011). Bioavailability of nanoparticles of ferric oxide when used in nutrition. Experimental results in rats. Voprosy Pitaniya 80(3), 25-30. 
Salvia-Trujillo, L., Qian, C., Martin-Belloso, O., and McClements, D. J. (2013). Influence of particle size on lipid digestion and beta-carotene bioaccessibility in emulsions and nanoemulsions. Food Chemistry 141(2), 1472-1480, 10.1016/j.foodchem.2013.03.050.

Salvia-Trujillo, L., Sun, Q., Um, B. H., Park, Y., and McClements, D. J. (2015). In vitro and in vivo study of fucoxanthin bioavailability from nanoemulsion-based delivery systems: Impact of lipid carrier type. Journal of Functional Foods 17, 293-304.

Sandra, S., Decker, E. A., and McClements, D. J. (2008). Effect of interfacial protein crosslinking on the in vitro digestibility of emulsified corn oil by pancreatic lipase. Journal of agricultural and food chemistry 56(16), 7488-94, 10.1021/jf800741w.

Seok, S. H., Cho, W. S., Park, J. S., Na, Y., Jang, A., Kim, H., Cho, Y., Kim, T., You, J. R., Ko, S., Kang, B. C., Lee, J. K., Jeong, J., and Che, J. H. (2013). Rat pancreatitis produced by 13week administration of zinc oxide nanoparticles: biopersistence of nanoparticles and possible solutions. Journal of applied toxicology : JAT 33(10), 1089-96, 10.1002/jat.2862.

Sharma, S., Singh, J., Ojha, R., Singh, H., Kaur, M., Bedi, P. M., and Nepali, K. (2016). Design strategies, structure activity relationship and mechanistic insights for purines as kinase inhibitors. European journal of medicinal chemistry 112, 298-346, 10.1016/j.ejmech.2016.02.018.

Shin, G. H., Kim, J. T., and Park, H. J. (2015). Recent developments in nanoformulations of lipophilic functional foods. Trends in Food Science \& Technology 46(1), 144-157, 
10.1016/j.tifs.2015.07.005.

Silletti, E., Vingerhoeds, M. H., Norde, W., and Van Aken, G. A. (2007). The role of electrostatics in saliva-induced emulsion flocculation. Food Hydrocolloids 21(4), 596-606, 10.1016/j.foodhyd.2006.07.004.

Singh, G., Stephan, C., Westerhoff, P., Carlander, D., and Duncan, T. V. (2014). Measurement Methods to Detect, Characterize, and Quantify Engineered Nanomaterials in Foods.

Comprehensive Reviews in Food Science and Food Safety 13(4), 693-704, 10.1111/15414337.12078.

Sisler, J. D., Pirela, S. V., Friend, S., Farcas, M., Schwegler-Berry, D., Shvedova, A., Castranova, V., Demokritou, P., and Qian, Y. (2015). Small airway epithelial cells exposure to printer-emitted engineered nanoparticles induces cellular effects on human microvascular endothelial cells in an alveolar-capillary co-culture model. Nanotoxicology 9(6), 769-79, 10.3109/17435390.2014.976603.

So, S. J., Jang, I. S., and Han, C. S. (2008). Effect of micro/nano silica particle feeding for mice. Journal of nanoscience and nanotechnology 8(10), 5367-71.

Sotiriou, G. A., Watson, C., Murdaugh, K. M., Darrah, T. H., Pyrgiotakis, G., Elder, A., Brain, J. D., and Demokritou, P. (2014). Engineering safer-by-design, transparent, silica-coated $\mathrm{ZnO}$ nanorods with reduced DNA damage potential. Environmental science. Nano 1(2), 144-153, 
10.1039/c3en00062a.

Sycheva, L. P., Zhurkov, V. S., Iurchenko, V. V., Daugel-Dauge, N. O., Kovalenko, M. A., Krivtsova, E. K., and Durnev, A. D. (2011). Investigation of genotoxic and cytotoxic effects of micro- and nanosized titanium dioxide in six organs of mice in vivo. Mutation research 726(1), 8-14, 10.1016/j.mrgentox.2011.07.010.

Szakal, C., Roberts, S. M., Westerhoff, P., Bartholomaeus, A., Buck, N., Illuminato, I., Canady, R., and Rogers, M. (2014a). Measurement of Nanomaterials in Foods: Integrative Consideration of Challenges and Future Prospects. Acs Nano 8(4), 3128-3135, 10.1021/nn501108g.

Szakal, C., Roberts, S. M., Westerhoff, P., Bartholomaeus, A., Buck, N., Illuminato, I., Canady, R., and Rogers, M. (2014b). Measurement of nanomaterials in foods: integrative consideration of challenges and future prospects. ACS nano 8(4), 3128-35, 10.1021/nn501108g.

Szakal, C., Tsytsikova, L., Carlander, D., and Duncan, T. V. (2014c). Measurement Methods for the Oral Uptake of Engineered Nanomaterials from Human Dietary Sources: Summary and Outlook. Comprehensive Reviews in Food Science and Food Safety 13(4), 669-678, 10.1111/1541-4337.12080.

Taylor, J., Huefner, A., Li, L., Wingfield, J., and Mahajan, S. (2016). Nanoparticles and intracellular applications of surface-enhanced Raman spectroscopy. The Analyst 141(17), 503755, 10.1039/c6an01003b. 
Tenzer, S., Docter, D., Kuharev, J., Musyanovych, A., Fetz, V., Hecht, R., Schlenk, F., Fischer, D., Kiouptsi, K., Reinhardt, C., Landfester, K., Schild, H., Maskos, M., Knauer, S. K., and Stauber, R. H. (2013). Rapid formation of plasma protein corona critically affects nanoparticle pathophysiology. Nature nanotechnology 8(10), 772-81, 10.1038/nnano.2013.181.

Theriot, C. M., Koenigsknecht, M. J., Carlson, P. E., Jr., Hatton, G. E., Nelson, A. M., Li, B., Huffnagle, G. B., J, Z. L., and Young, V. B. (2014). Antibiotic-induced shifts in the mouse gut microbiome and metabolome increase susceptibility to Clostridium difficile infection. Nature communications 5, 3114, 10.1038/ncomms4114.

Turnbaugh, P. J., Ridaura, V. K., Faith, J. J., Rey, F. E., Knight, R., and Gordon, J. I. (2009). The effect of diet on the human gut microbiome: a metagenomic analysis in humanized gnotobiotic mice. Science translational medicine 1(6), 6ra14, 10.1126/scitranslmed.3000322.

Vingerhoeds, M. H., Blijdenstein, T. B. J., Zoet, F. D., and van Aken, G. A. (2005). Emulsion flocculation induced by saliva and mucin. Food Hydrocolloids 19(5), 915-922, 10.1016/j.foodhyd.2004.12.005.

Walkey, C. D., and Chan, W. C. (2012). Understanding and controlling the interaction of nanomaterials with proteins in a physiological environment. Chemical Society reviews 41(7), 2780-99, 10.1039/c1cs15233e. 
Wang, H., Du, L. J., Song, Z. M., and Chen, X. X. (2013). Progress in the characterization and safety evaluation of engineered inorganic nanomaterials in food. Nanomedicine (London, England) 8(12), 2007-25, 10.2217/nnm.13.176.

Warheit, D. B., Brown, S. C., and Donner, E. M. (2015). Acute and subchronic oral toxicity studies in rats with nanoscale and pigment grade titanium dioxide particles. Food and Chemical Toxicology 84, 208-224, 10.1016/j.fct.2015.08.026.

Watson, C., Ge, J., Cohen, J., Pyrgiotakis, G., Engelward, B. P., and Demokritou, P. (2014). High-throughput screening platform for engineered nanoparticle-mediated genotoxicity using CometChip technology. ACS nano 8(3), 2118-33, 10.1021/nn404871p.

Weir, A., Westerhoff, P., Fabricius, L., Hristovski, K., and von Goetz, N. (2012). Titanium Dioxide Nanoparticles in Food and Personal Care Products. Environ. Sci. Technol. 46(4), 2242$2250,10.1021 /$ es204168d.

Weir, T. L., Manter, D. K., Sheflin, A. M., Barnett, B. A., Heuberger, A. L., and Ryan, E. P. (2013). Stool microbiome and metabolome differences between colorectal cancer patients and healthy adults. PloS one 8(8), e70803, 10.1371/journal.pone.0070803.

Wilding, L. A., Bassis, C. M., Walacavage, K., Hashway, S., Leroueil, P. R., Morishita, M., Maynard, A. D., Philbert, M. A., and Bergin, I. L. (2016). Repeated dose (28-day) administration of silver nanoparticles of varied size and coating does not significantly alter the indigenous 
murine gut microbiome. Nanotoxicology 10(5), 513-20, 10.3109/17435390.2015.1078854.

Williams, K., Milner, J., Boudreau, M. D., Gokulan, K., Cerniglia, C. E., and Khare, S. (2015).

Effects of subchronic exposure of silver nanoparticles on intestinal microbiota and gut-associated immune responses in the ileum of Sprague-Dawley rats. Nanotoxicology 9(3), 279-89, 10.3109/17435390.2014.921346.

Wooster, T. J., Golding, M., and Sanguansri, P. (2008). Impact of Oil Type on Nanoemulsion Formation and Ostwald Ripening Stability. Langmuir : the ACS journal of surfaces and colloids 24(22), 12758-12765, 10.1021/la801685v.

Yada, R., Buck, N., Canady, R., Demerlis, C., Duncan, T., Janer, G., Juneja, L., Mengshi, L., McClements, D. J., Noonan, G., Oxley, J., Sabliov, C., Tsytsikova, L., Vazquez-Campos, S., Yourick, J., Zhong, Q., and Thurmond, S. (2014a). Engineered Nanoscale Food Ingredients: Evaluation of Current Knowledge on Material Characteristics Relevant to Uptake from the Gastrointestinal Tract. Comprehensive Reviews in Food Science and Food Safety 13(4), 730-744.

Yada, R. Y., Buck, N., Canady, R., DeMerlis, C., Duncan, T., Janer, G., Juneja, L., Lin, M., McClements, D. J., Noonan, G., Oxley, J., Sabliov, C., Tsytsikova, L., Vazquez-Campos, S., Yourick, J., Zhong, Q., and Thurmond, S. (2014b). Engineered Nanoscale Food Ingredients: Evaluation of Current Knowledge on Material Characteristics Relevant to Uptake from the Gastrointestinal Tract. Comprehensive Reviews in Food Science and Food Safety 13(4), 730-744, $10.1111 / 1541-4337.12076$. 
Yao, M., Chen, J., Zheng, J., Song, M., McClements, D. J., and Xiao, H. (2013). Enhanced lymphatic transport of bioactive lipids: cell culture study of polymethoxyflavone incorporation into chylomicrons. Food \& function 4(11), 1662-7, 10.1039/c3fo60335k.

Yao, M., He, L., McClements, D. J., and Xiao, H. (2015a). Uptake of Gold Nanoparticles by Intestinal Epithelial Cells: Impact of Particle Size on Their Absorption, Accumulation, and Toxicity. Journal of agricultural and food chemistry 63(36), 8044-9, 10.1021/acs.jafc.5b03242.

Yao, M., McClements, D. J., and Xiao, H. (2015b). Improving oral bioavailability of nutraceuticals by engineered nanoparticle-based delivery systems. Current Opinion in Food Science 2, 14-19, 10.1016/j.cofs.2014.12.005.

Yao, M., Xiao, H., and McClements, D. J. (2014). Delivery of lipophilic bioactives: assembly, disassembly, and reassembly of lipid nanoparticles. Annual review of food science and technology 5, 53-81, 10.1146/annurev-food-072913-100350.

Yokel, R. A., Hussain, S., Garantziotis, S., Demokritou, P., Castranova, V., and Cassee, F. R. (2014). The Yin: An adverse health perspective of nanoceria: uptake, distribution, accumulation, and mechanisms of its toxicity. Environmental science. Nano 1(5), 406-428, 10.1039/c4en00039k.

Zattoni, A., Roda, B., Borghi, F., Marassi, V., and Reschiglian, P. (2014). Flow field-flow 
fractionation for the analysis of nanoparticles used in drug delivery. Journal of pharmaceutical and biomedical analysis 87, 53-61, 10.1016/j.jpba.2013.08.018.

Zeeb, B., Weiss, J., and McClements, D. J. (2015). Electrostatic modulation and enzymatic crosslinking of interfacial layers impacts gastrointestinal fate of multilayer emulsions. Food Chem 180, 257-64, 10.1016/j.foodchem.2015.02.048.

Zhang, Y., Ferguson, S. A., Watanabe, F., Jones, Y., Xu, Y., Biris, A. S., Hussain, S., and Ali, S. F. (2013). Silver nanoparticles decrease body weight and locomotor activity in adult male rats. Small (Weinheim an der Bergstrasse, Germany) 9(9-10), 1715-20, 10.1002/smll.201201548.

Zhou, E. H., Watson, C., Pizzo, R., Cohen, J., Dang, Q., Ferreira de Barros, P. M., Park, C. Y., Chen, C., Brain, J. D., Butler, J. P., Ruberti, J. W., Fredberg, J. J., and Demokritou, P. (2014). Assessing the impact of engineered nanoparticles on wound healing using a novel in vitro bioassay. Nanomedicine (London, England) 9(18), 2803-15, 10.2217/nnm.14.40.

Zimmermann, M. B., and Hilty, F. M. (2011). Nanocompounds of iron and zinc: their potential in nutrition. Nanoscale 3(6), 2390-2398, 10.1039/c0nr00858c.

Zou, L., Liu, W., Liu, C., Xiao, H., and McClements, D. J. (2015a). Designing excipient emulsions to increase nutraceutical bioavailability: emulsifier type influences curcumin stability and bioaccessibility by altering gastrointestinal fate. Food \& function 6(8), 2475-86, 10.1039/c5fo00606f. 
Zou, L., Liu, W., Liu, C., Xiao, H., and McClements, D. J. (2015b). Utilizing food matrix effects to enhance nutraceutical bioavailability: increase of curcumin bioaccessibility using excipient emulsions. Journal of agricultural and food chemistry 63(7), 2052-62, 10.1021/jf506149f.

Zou, L., Zheng, B., Zhang, R., Zhang, Z., Liu, W., Liu, C., Xiao, H., and McClements, D. J. (2016). Food-grade nanoparticles for encapsulation, protection and delivery of curcumin: comparison of lipid, protein, and phospholipid nanoparticles under simulated gastrointestinal conditions. RSC Advances 6(4), 3126-3136, 10.1039/C5RA22834D.

\section{FIGURE LEGENDS}

Figure 1. A variety of structures can be assembled using lipid nanoparticles as building blocks, including nanoparticle filled droplets and hydrogels, nanoparticle clusters, nanoparticle colloidosomes, solid lipid nanoparticles, and nanolaminated nanoparticles (McClements, 2012; McClements, 2014) .

Figure 2. Food grade nanoparticles may vary in particle characteristics, such as size, shape, composition, and charge.

Figure 3. Schematic diagram of the physicochemical and physiological conditions in different regions of the human gastrointestinal tract. The diagram of the human body was taken from 
http://en.wikipedia.org/wiki/Digestive_tract (Copyright free).

Figure 4. The properties of nanoparticles may occur in a number of different ways as they pass through the GIT. Some potential changes in particle dimensions and interfacial properties are illustrated here. 


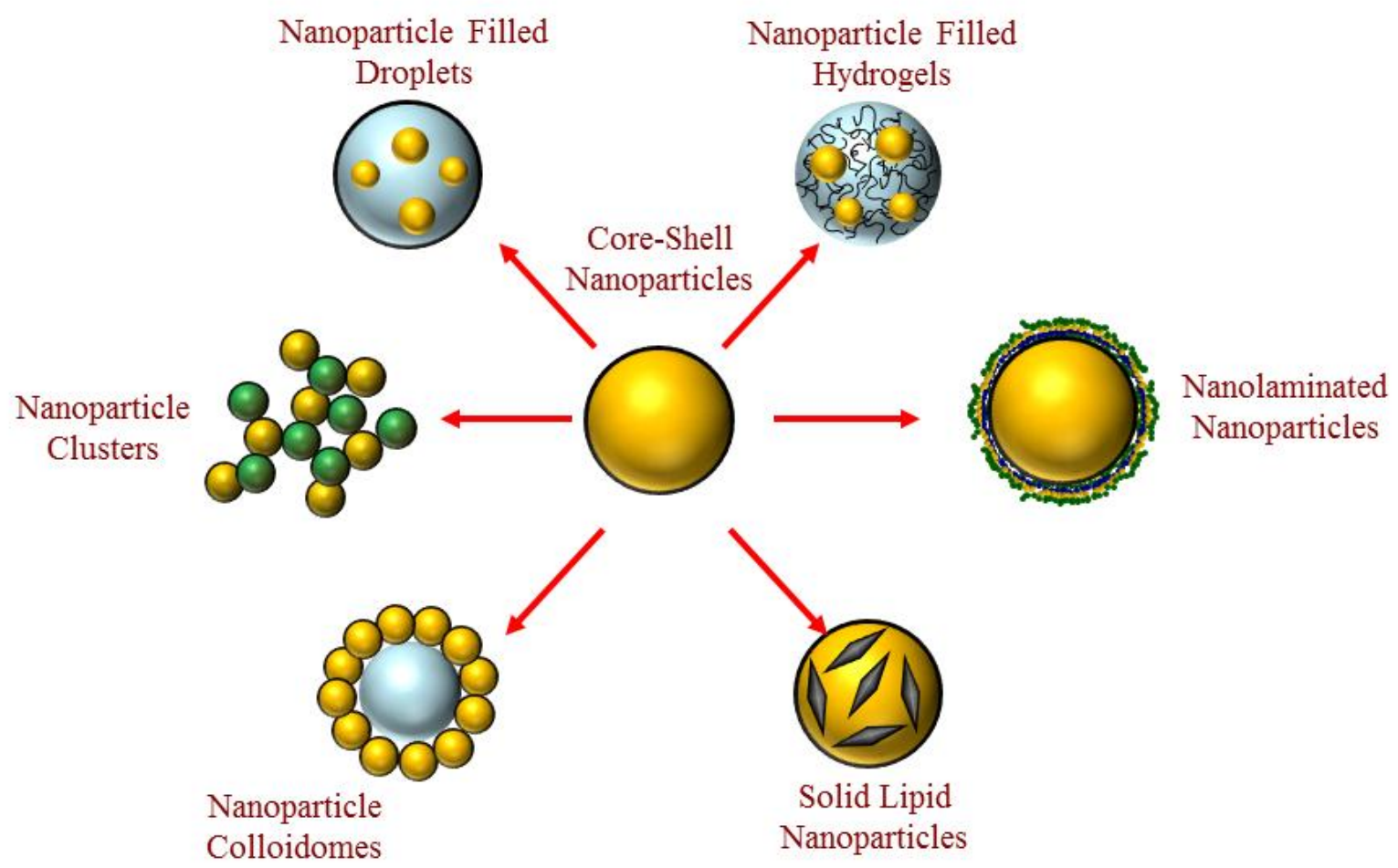




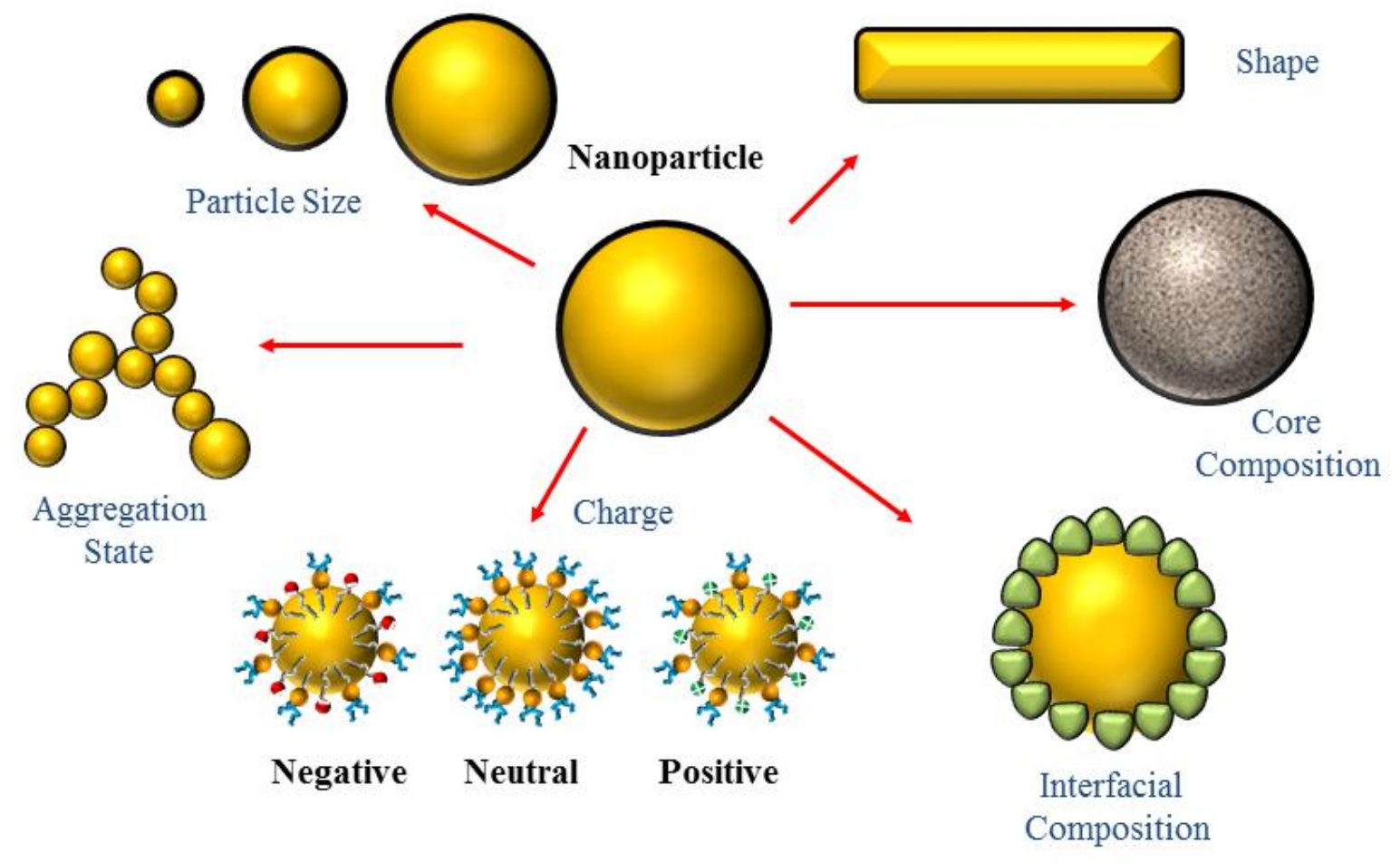




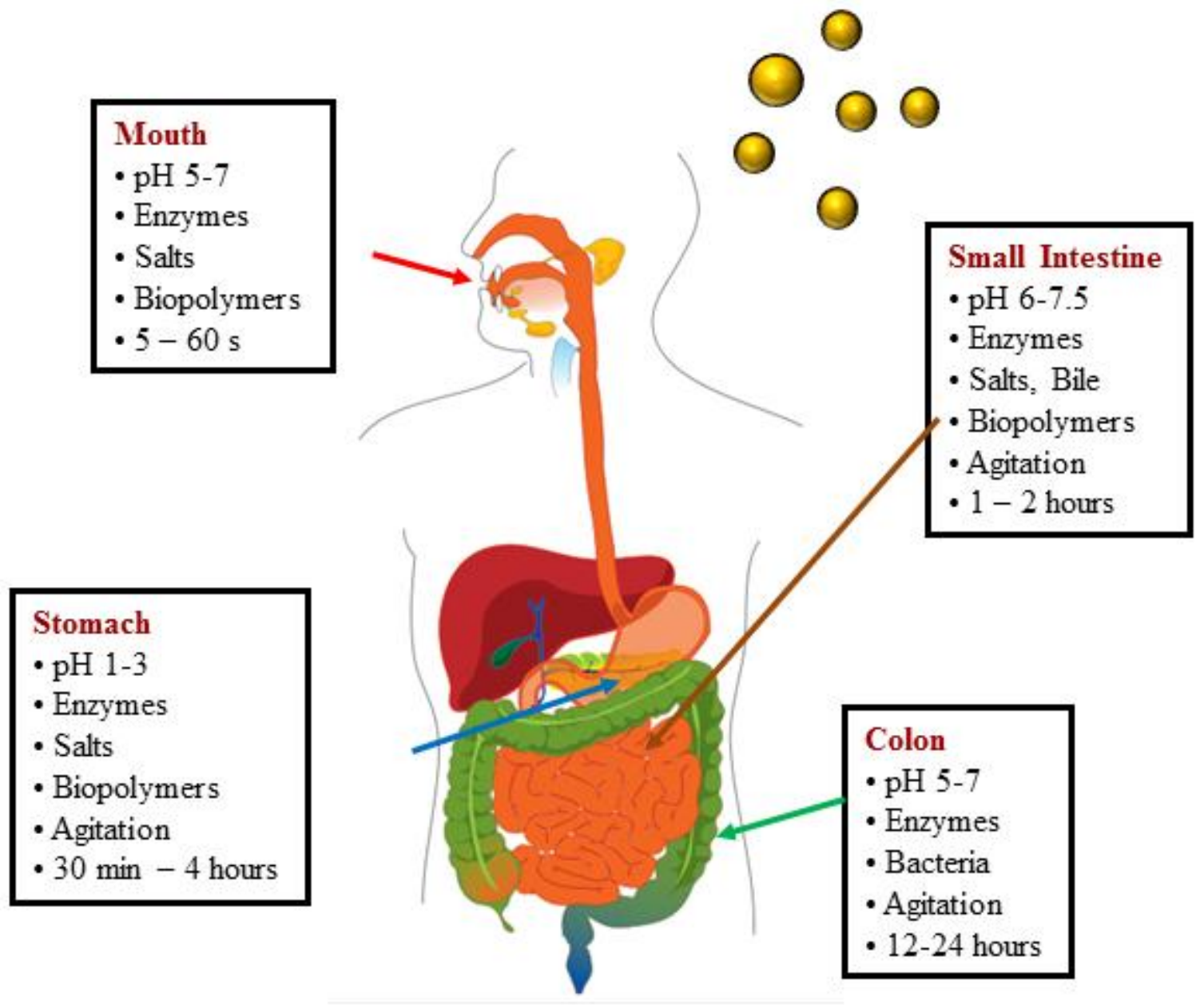




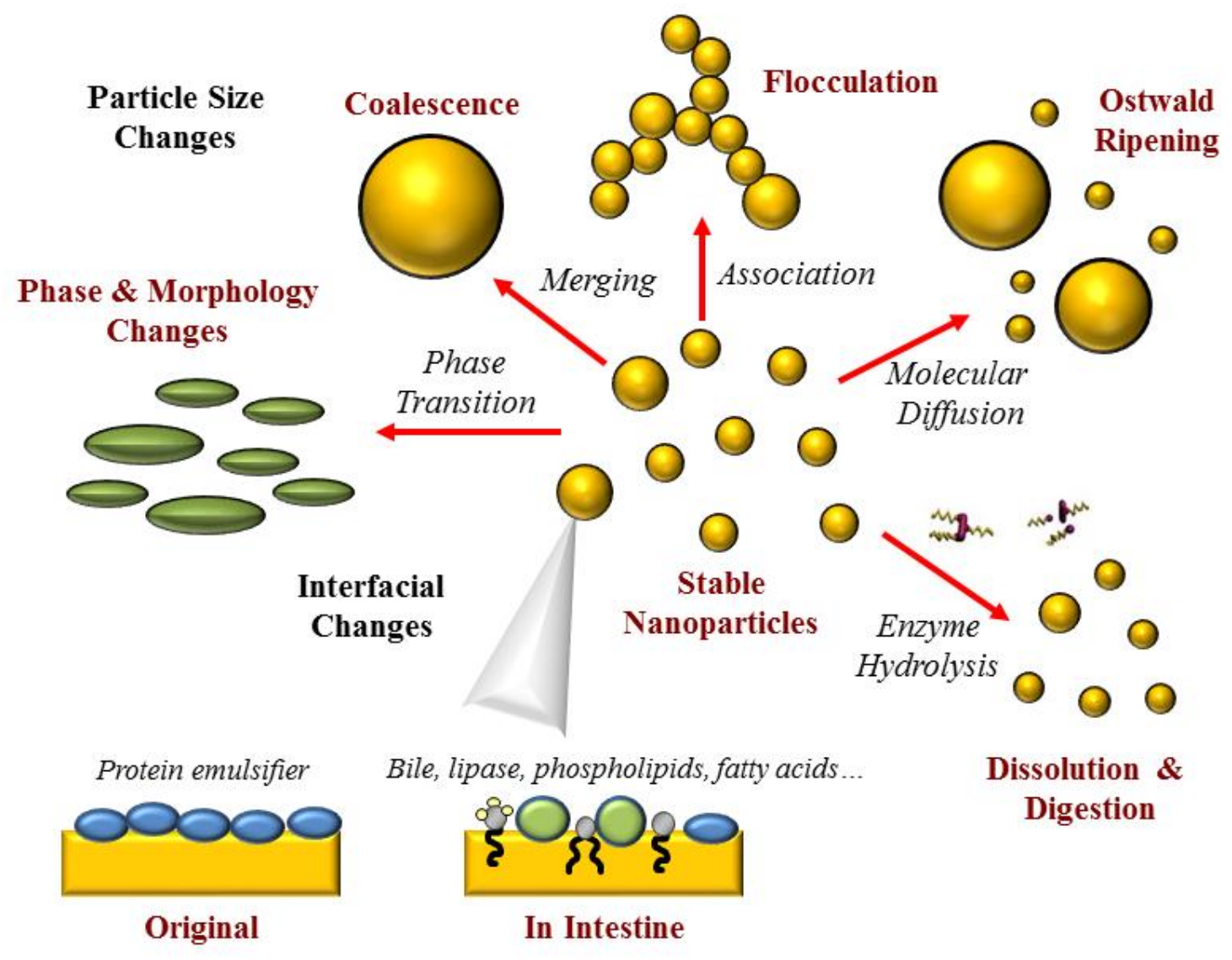




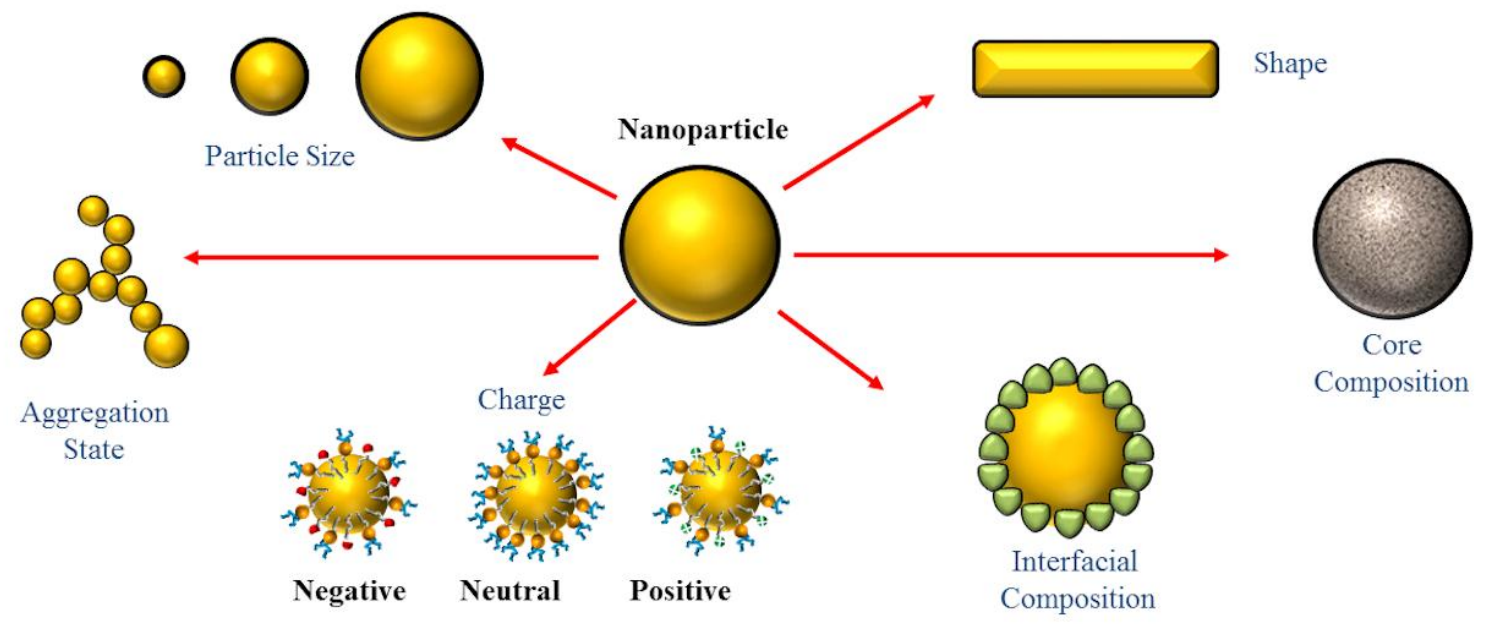

